\title{
Tendencias recientes en los cultivos y la producción ganadera en la provincia de Buenos Aires. Una mirada desde sus regiones productivas
}

Bona, Leandro*

\section{Resumen}

La provincia de Buenos Aires es el epicentro de la producción agropecuaria en Argentina, a juzgar por su participación en la producción de los principales cultivos de exportación y ganado bovino. Dentro de su territorio, su geografía es diversa y cuenta con regiones de muy distinta especialización, donde históricamente han prevalecido actividades agrícolas, ganaderas o de rotación. El propósito de este estudio es examinar el impacto de las políticas recientes (particularmente en los últimos diez años) sobre la producción de los principales cultivos y el ganado en la provincia, así como sobre la concentración y las exportaciones a nivel agregado. Para ello, se discriminan las regiones bonaerenses, se observan los principales resultados productivos a la luz de los cambios producidos recientemente y se examina el desempeño exportador y de las escalas de propiedad gracias a los resultados preliminares del Censo Nacional Agropecuario 2018.

Palabras clave: provincia de Buenos Aires; soja; ganadería; exportaciones agropecuarias; concentración

Este trabajo fue realizado en el marco del proyecto «Condicionamientos estructurales, macroeconómicos y sectoriales, y sus manifestaciones en el sector externo» (PICT-2016-3306) patrocinado por la Agencia Nacional de Promoción Científica y Tecnológica de la SECYT, en el Área de Economía y Tecnología de FLACSO. Recibido el 27/04/2020 y aceptado el 29/09/2020. Publicado el 02/05/2021.

DOI: $\underline{\text { https://10.33255/3262/775 }}$

Autoría: *Universidad Nacional de La Plata (Argentina).

Contacto: leandrombona@gmail.com 
Bona, Leandro I Tendencias recientes en los cultivos y la producción ganadera en la provincia de Buenos Aires...

Recent trends in export crops and livestock production in the province of Buenos Aires. A look based on its productive regions

\begin{abstract}
The province of Buenos Aires is the epicenter of agricultural production in Argentina, if we take into account its participation in the production and main export of crops and meat. Within its territory, its geography is diverse and has regions of very different specialization, where historically agricultural, livestock or rotation activities have prevailed. The purpose of this study is to examine the impact of recent policies (particularly in the last 10 years) on the production of the main crops and livestock in the province, as well as on concentration and exports on aggregate level. For this purpose, province regions are discriminated, main productive results are observed in relation to recent changes and the export performance and ownership scales are examined, based on preliminary results of the 2018 National Argentinian Census of Agriculture.
\end{abstract}

Keywords: province of Buenos Aires; soy; cattle raising; agricultural exports; concentration

Tendências recentes na agricultura e a produção de gado na província de Buenos Aires. Um olhar desde suas regiões produtivas

\title{
Resumo
}

A província de Buenos Aires é o epicentro da produção agropecuária da Argentina, considerando sua participação na produção dos principais cultivos de exportação e de gado bovino. Dentro de seu território, a sua geografia é diversa e apresenta regiões de especializações muito diferentes, onde historicamente prevalecem as atividades agrícolas, pecuárias ou de rotação. 0 objetivo deste estudo é examinar o impacto das políticas recentes (particularmente nos últimos 10 anos) sobre a produção dos principais cultivos e pecuária na província, bem como sobre a concentração e as exportações a nível agregado. Para isso, são discriminadas as regiões de Buenos Aires, observam-se os principais resultados produtivos à luz das mudanças produzidas recentemente e examina-se o desempenho exportador e as escalas de propriedade graças aos resultados preliminares do Censo Nacional Agropecuário 2018.

Palavras-chave: província de Buenos Aires; soja; pecuária; exportações agropecuárias; concentração 
Bona, Leandro I Tendencias recientes en los cultivos y la producción ganadera en la provincia de Buenos Aires...

\section{Introducción}

El sector agropecuario exportador tiene una importancia fundamental en la economía política argentina. Por este motivo, existen numerosos trabajos que han analizado la evolución económica y social del país con el acento en las condiciones de inserción en el mercado mundial y, por ende, del desarrollo de la agricultura y la ganadería, que históricamente colocó una buena parte de la producción en los mercados externos.

El comportamiento del sector cobró una centralidad renovada en el debate económico en los años 2000, gracias a un ciclo excepcional de incremento de los precios internacionales de los principales commodities agrícolas en los mercados extranjeros. Ese proceso se combinó con una «revolución tecnológica» que data de mediados de los años 90, cuando se incrementó el uso de paquetes genéticamente modificados de semillas y nuevos fertilizantes, herbicidas y técnicas de producción (tanto en agricultura como en ganadería). En ese contexto, el país anotó significativos incrementos en las exportaciones agropecuarias en la primera década del siglo XXI, que pasaron luego a estancarse desde 2012, cuando arreció nuevamente el problema de la restricción externa al crecimiento (es decir, la escasez de divisas necesarias para sostener los niveles de producción y empleo) (Wainer, 2018). El período coincidió con la creciente intensificación de la disputa entre vastos sectores propietarios y empresariales del sector contra las políticas intervencionistas del gobierno nacional (Cantamutto y López, 2018). Más adelante, la gestión económica desarrollada durante la presidencia de Mauricio Macri (2015-2019) se propuso implementar una serie de cambios normativos y regulatorios sobre el sector, con el propósito de relanzar la producción, inversiones y exportaciones.

La provincia de Buenos Aires tiene una importancia capital en la producción agropecuaria nacional, pues en sus 37 millones de hectáreas se ubica cerca del $50 \%$ de la superficie sembrada del país y aquí se concentra aproximadamente el $56 \%$ del total de exportaciones bovinas, el $44 \%$ de las de cereales y el $32 \%$ de las oleaginosas del país (Observatorio de Bioeconomía, 2019). Más allá de su relevancia global, su geografía es muy diversa y cuenta con regiones de muy distinta especialización, donde históricamente han prevalecido actividades agrícolas, ganaderas o de rotación.

El propósito de este estudio es examinar la evolución de la producción agropecuaria en el territorio bonaerense, así como las tendencias respecto de la concentración de la propiedad y su impacto en el sector externo, en el marco de los cambios en las condiciones internacionales (precios internacionales y demanda) y algunas de las principales políticas sectoriales, cambiarias 
y comerciales en el período 2002-2019, con particular interés en los cambios entre 2012-2015 y 2016-2019. Con este objetivo, se discriminan las regiones productivas a partir de la propuesta del Ministerio de Economía de la Provincia de Buenos Aires (2011), se observan los principales resultados productivos y se evalúa el desempeño exportador y de las escalas de propiedad gracias a los resultados preliminares del Censo Nacional Agropecuario 2018.

Para alcanzar esta tarea, este trabajo se organiza como sigue: después de esta introducción, en el primer apartado se presenta brevemente el marco teórico y la selección de políticas económicas que se tomarán en cuenta para evaluar los cambios en las condiciones internas de desempeño del sector. En el siguiente segmento se realiza un breve recorrido sobre la relevancia y los cambios del desarrollo agropecuario, con especial énfasis en las transformaciones del siglo XXI de acuerdo al contexto internacional y las políticas públicas específicas seleccionadas en este período. En el tercer apartado se presenta la estructura de las regiones delimitadas y los criterios empleados para tal fin, y se analiza la evolución de las principales tendencias en materia de la siembra de los principales cultivos (soja, maíz, trigo, girasol, y en algunos casos, cebada) y la ganadería. Luego, se analizan evidencias sobre la concentración productiva y el desempeño comercial de la provincia con foco en las explotaciones y exportaciones agropecuarias. El trabajo cierra con breves reflexiones finales.

\section{Marco teórico y políticas económicas analizadas}

Para el análisis de los cambios estructurales en el sector agroexportador de la provincia de Buenos Aires, se emplea la tradición del pensamiento latinoamericano, en torno a la relevancia de este sector en el comportamiento macroeconómico, en particular de la cuenta corriente (Prebisch, 1949; Furtado, 1972; Diamand, 1973). Dichos estudios señalan la necesidad de recurrir al método histórico estructural para la comprensión de los fenómenos económicos en países como Argentina, por lo que es necesario examinar la evolución del sector agrario exportador a lo largo de los distintos patrones de acumulación (Arceo, 2003).

El concepto de patrón o régimen de acumulación alude a la articulación de un determinado funcionamiento de las variables económicas, vinculado a una definida estructura económica, una peculiar forma de Estado y las luchas entre los bloques sociales existentes. Esto permite inscribir el ejercicio de los actores sociales del sector agropecuario, así como los cambios que imprimen sus tendencias productivas, en los procesos de acumulación 
de capital a escala nacional bajo las condiciones internacionales (Basualdo, 2010; Arceo y otros, 2009).

De acuerdo a este enfoque, las políticas económicas (fiscales, monetarias, financieras, sociales) se examinan en base a su consistencia con los distintos patrones de acumulación (Basualdo, 2019). Para los propósitos de este trabajo, se analizan algunas de las principales políticas que modifican el entorno del sector agroexportador, jerarquizadas en tres ejes:

- cambiarias: tipo de cambio y precios relativos (tarifas de insumos como combustible y forraje)

- sectoriales: permisos, cupos y reintegros a las exportaciones

- comerciales: derechos sobre las exportaciones (retenciones), segmentación de las mismas y régimen de liquidación de divisas.

Estas políticas describen los principales lineamientos de la política regulatoria y normativa sectorial, y por lo tanto son revisadas con el fin de evaluar sus impactos en el sector agroexportador en la provincia de Buenos Aires, en un ejercicio de discriminación por áreas productivas.

\section{El peso agrario en Argentina y los cambios normativos y coyunturales recientes}

Desde sus albores como nación, la forma de inserción de Argentina en el mercado mundial ha sido como proveedora de materias primas, fundamentalmente hacia Europa. Por este motivo, el país desarrolló un sistema de producción, absorción de mano de obra, transporte y legislación articulado en torno a las exportaciones de bienes primarios durante el siglo XIX (Arceo, 2003). Por caso, vale citar la construcción de una red ferroviaria en forma de abanico que desembocaba en el puerto de Buenos Aires, siendo esta provincia la de mayor peso poblacional y productivo del país. De este modo, las ventas externas de carnes y cereales se constituyeron en la variable clave del proyecto económico hasta las primeras décadas del siglo XX. Al respecto, distintos autores y autoras coinciden en que el país transitó durante el siglo $X X$ tres regímenes de acumulación: el modelo agroexportador (hasta la década del 30), el período de sustitución de importaciones (desde los años 30 hasta mediados de la década del 70) y la valorización financiera (1976-2001) (Basualdo, 2010; Ferrer, 2008).

Los debates en torno a la generación, apropiación y destino de la renta agropecuaria, por ende, ocuparon un lugar destacado en el debate académico y político (Iñigo Carrera, 2007). Después del aliento agroexportador, la crisis de los años 30 impuso nuevas condiciones externas, donde, en el marco de la 
reducción del comercio exterior, se produjo un viraje «hacia adentro». Entonces, durante la etapa sustitutiva se examinó al agro a partir de la problemática de la restricción externa al crecimiento: el sector primario contaba con altos niveles de productividad y proveía las divisas, en tanto que la industria tenía rezagos tecnológicos y registraba déficits comerciales. En este sentido, la incapacidad de ampliar la producción agropecuaria exportadora (concentrada fundamentalmente en la provincia de Buenos Aires y parte del sur de Córdoba y Santa Fe) y, por ende, la provisión de divisas, socavaba las posibilidades de financiar los insumos manufactureros, crecientemente necesarios en contextos de expansión (debido a su dependencia importadora) (Braun, 1970). También se analizaron las alianzas de distintas fracciones de clases en el marco de los debates sobre los movimientos del tipo de cambio, los derechos de exportación e importación, los subsidios a las tarifas de servicios públicos, los controles cambiarios, las negociaciones paritarias, entre otras decisiones de política económica (O’Donnell, 1977).

El debate cambió de eje al multiplicarse los canales financieros para la provisión de divisas, lo que ocurrió a partir de la puesta en marcha de la valorización financiera inaugurada por la dictadura cívico-militar en 1976. La misma consiste en:

la colocación de excedente por parte de las grandes firmas en diversos activos financieros (títulos, bonos, depósitos, etc.) en el mercado interno e internacional. Este proceso, que irrumpe y es predominante en la economía argentina desde fines de la década de los años setenta, se expande debido a que las tasas de interés, o la vinculación entre ellas, supera la rentabilidad de las diversas actividades económicas, y a que el acelerado crecimiento del endeudamiento externo posibilita la remisión de capital local al exterior al operar como una masa de excedente valorizable y/o al liberar las utilidades para esos fines. (Arceo y Basualdo, 1999: 41)

A partir de allí se verificó entonces un desplazamiento de la producción ganadera y agrícola, que anteriormente funcionaba bajo el concepto de «ciclo ganadero»: cuando crecía la rentabilidad relativa de la ganadería, se ocupaban las tierras disponibles con bovinos, en tanto si se incrementaban los retornos del sector agrícola, se desplazaba la ganadería para sembrar cereales y oleaginosas. Desde 1976 terció un nuevo rendimiento en el análisis de las inversiones: la tasa de interés, que al operar libremente y elevarse considerablemente durante el período 1976-1981, pasó a aportar mayores rendimientos que sus competidores, la ganadería y la agricultura (Basualdo, 2008). Más allá de este 
fenómeno, se observó también un cambio de paradigma en la producción, la «revolución verde», que se basó en la incorporación de tecnologías agrícolas (herbicidas, fertilizantes, semillas híbridas) que permitirían incrementar significativamente la productividad (Pérez Trento, 2019).

En estas condiciones, si bien entre 1976 y 1995 la superficie sembrada se mantuvo relativamente estable (en el orden de los 20 millones de hectáreas), aumentó considerablemente el rendimiento: la producción pasó de 40 a 60 millones de toneladas (un $50 \%$ más). Una de las claves pasaba por el creciente peso de la soja, un cultivo que resultaba insignificante en los años 70 y que ya para mediados de los 90 ocupaba un cuarto de la superficie sembrada. La provincia de Buenos Aires lideró este fenómeno, al concentrar buena parte en la zona núcleo pampeana, caracterizada por su elevada productividad (Basualdo y otros, 2019).

La gran transformación se produciría precisamente en la década del 90, en pleno desarrollo como «etapa superior» de la valorización financiera, y daría como resultado un aumento notable de la productividad agrícola. El factor decisivo fue la introducción del nuevo paradigma productivo, sustentado en la soja transgénica (Trigo, 2016). A principios de 1996, la Secretaría de Agricultura, Ganadería y Pesca, a través de una resolución, aprobó el uso comercial de la soja RR, un desarrollo de la empresa Monsanto que produjo semillas que incorporaron un evento biotecnológico para resistir al herbicida glifosato. La producción de la «oleaginosa estrella» pasó de una producción de 12 a 30 millones de toneladas entre las campañas 1991/1992 y 2000/01, para luego trepar a prácticamente 60 millones en 2015/16. Al mismo tiempo se expandió el uso de la maquinaria de punta y se difundió rápidamente la siembra directa que, al no exigir la roturación de la tierra, disminuyó el costo y la erosión del terreno. Asimismo, se verificó una reestructuración del mapa de actores agrarios, con la multiplicación de empresas de servicios (financieros, de arrendamiento, de transporte, etc.), contratistas, proveedores de insumos, inversores externos, entre otros (Anlló y otros, 2015).

La expansión sojera y agrícola desde 1996 se produjo en desmedro de la ganadería y, como consecuencia de ello, los bovinos pasaron a trasladarse hacia zonas menos fértiles (Santarcángelo y Fal, 2009). Incidieron allí también las relativas desventajas de la ganadería en relación con la agricultura, pues el ganado es a la vez una mercancía de consumo y de capital, cuenta con elevados costos de entrada y salida del mercado, insume mano de obra de manera permanente (a diferencia de buena parte de la agricultura, que reviste un carácter transitorio) y tiene un plazo de capitalización de la inversión de al menos tres años. En este contexto, la ganadería se redefinió y la actividad 
intensificó la cantidad de animales por hectárea, a través del incremento de la suplementación alimentaria con mejoras de pasturas y el finish-lot (que reemplaza la invernada tradicional con intensificación del engorde final a corral) (Biodiversidad en América Latina y el Caribe, 2011). De este modo, se avanzó con un modelo de mayor complejidad en la dinámica de las inversiones y el uso del suelo (Pordomingo, 2013).

Tras la salida de la convertibilidad, que estuvo marcada por la mayor devaluación de la historia argentina, en el año 2002 se elevaron significativamente los retornos del sector primario-exportador (Gráfico 1). El «tipo de cambio alto» transfirió elevados ingresos al sector exportador (Azpiazu y otros, 2011) y por ello, el incremento en la renta agraria fue parcialmente compensado con la colocación de derechos de exportación sobre productos primarios: 5 \% para carnes y lácteos, $10 \%$ para otros productos primarios como frutas y hortalizas y $20 \%$ para cereales y oleaginosas. Con el incremento de los precios, estos porcentajes irían incrementándose en años posteriores.

Las actividades primarias tuvieron un fuerte impulso, que se combinó con un período singular de incrementos de precios de los principales commodities de exportación (especialmente soja), entre 2002 y 2008. De esta manera, el crecimiento en siembra y producción se transformó en un salto de exportaciones y renta (Sturzenegger, 2015).

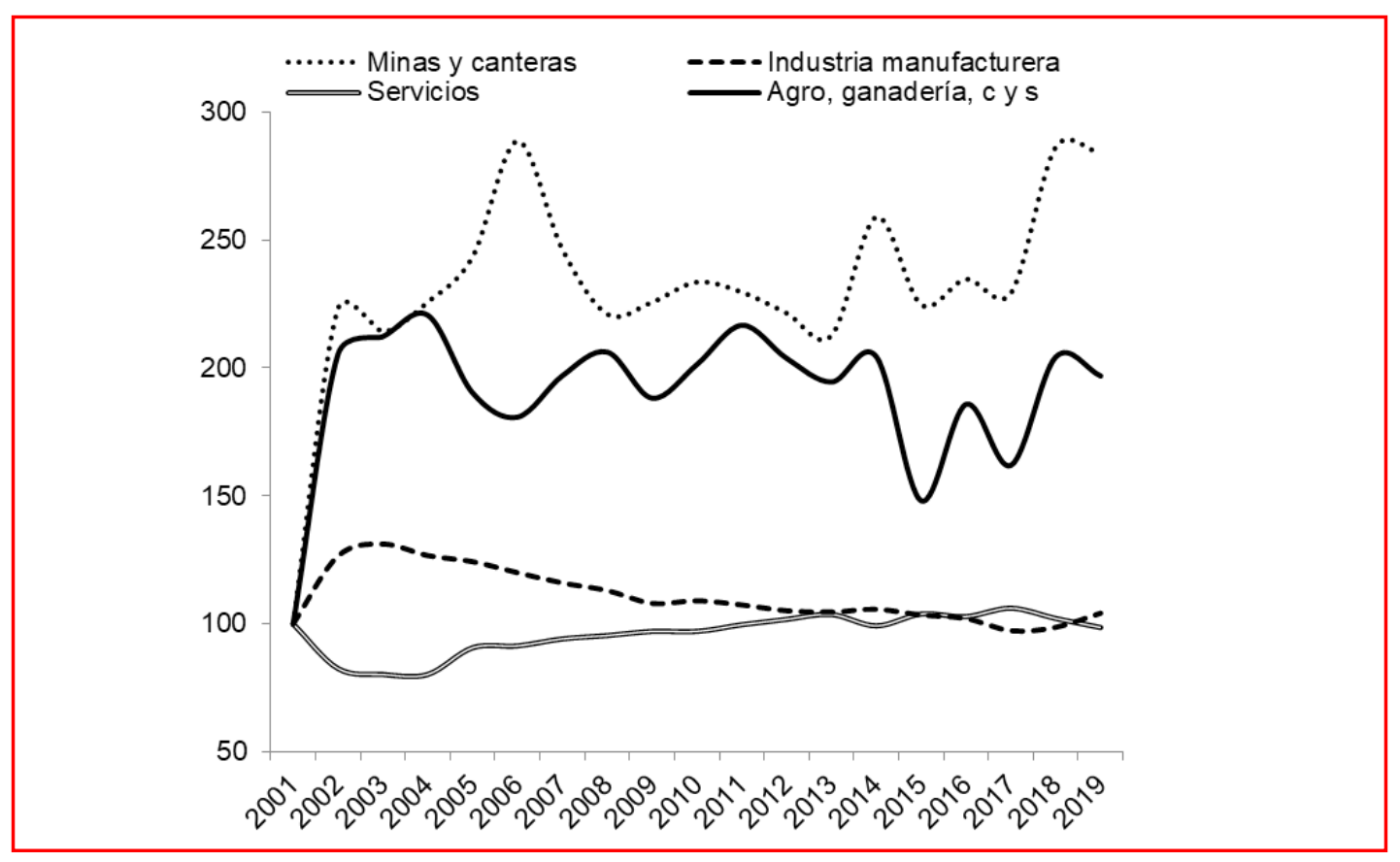

Gráfico 1. Evolución de los precios relativos de sectores seleccionados`. Años 2001-2019. Base 2001=100 Fuente: Elaboración propia en base a FLACSO e INDEC.`Agricultura y ganadería incluye caza y silvicultura. 
En este escenario, el ciclo de posconvertibilidad iniciado en 2002 y caracterizado por los gobiernos kirchneristas (2003-2015) marcaría distancias en relación con el período de la valorización financiera en una serie de políticas y resultados económicos y sociales (tendencias al aumento de los salarios y el empleo, mayores regulaciones sectoriales y reversión del endeudamiento externo, etc.) (Basualdo, 2017), aunque en el sector agropecuario las grandes tendencias descritas antes continuaron su curso. En particular, la soja genéticamente modificada y la ampliación del paquete tecnológico hacia los demás cultivos de exportación prosiguieron su expansión gracias a la demanda china (Bona, 2021). Por cierto, si bien este modelo transgénico reportó crecientes divisas gracias al aumento de rindes, generó un desplazamiento de cultivos tradicionales y ganado, además de ser objeto de críticas medioambientales y

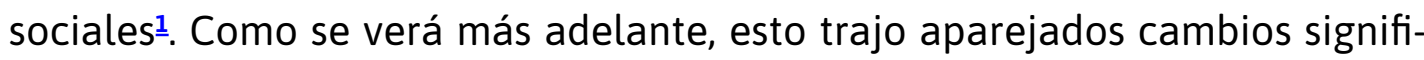
cativos en la geografía bonaerense.

Durante el período 2002-2012, los retornos del sector agrícola crecieron de manera significativa tanto por producción como por el ciclo alcista de los precios de los commodities de exportación: la renta agraria de los cuatro principales cultivos de exportación (soja, maíz, trigo y girasol) aumentó de USD 3.069 millones en el año 2002 a USD 27.224 millones en 2008, para luego reducirse a USD 20.295 millones en 2012 (Palmieri, 2015)². Esta significativa masa de divisas y riqueza generaría profundos debates en torno a su apropiación durante los gobiernos kirchneristas, lo que se reflejó en la política de derechos de exportación, particularmente en el conflicto por el establecimiento de retenciones móviles en 2008 (Arceo y otros, 2009).

Desde el punto de vista de las políticas cambiarias, se verificó una erosión del «tipo de cambio alto» entre 2011 y 2015, en un contexto de pujas devaluatorias (Wainer, 2016). Sin embargo, la política de subsidios a las tarifas de energía y combustible, que significaron un congelamiento de precios en un contexto de inflación, continuó gravitando como vector de «competitividad» (Bona, 2021). En lo que respecta a las políticas sectoriales y comerciales, a lo largo de los gobiernos kirchneristas se impusieron trámites, permisos y cupos de exportación, se estableció la obligatoriedad de la liquidación de divisas por parte de los exportadores y desde 2011 se implementaron controles cambiarios (requisitos para administrar la moneda extranjera), en el marco de la restricción externa (Wainer, 2018). De esta manera a fines del segundo mandato de Cristina Fernández (2011-2015) los precios implícitos del sector eran los más deprimidos desde 2001 (Gráfico 1), con retenciones sobre soja del $35 \%$ (porotos) y $32 \%$ (derivados), sobre girasol del $32 \%$ (semillas) y $30 \%$ (derivados), del $23 \%$ y $13 \%$ para trigo y harina respectivamente, del $20 \%$ para 
maíz, sorgo y cebada, y del $15 \%$ para carne vacuna. Un enfoque intervencionista que generó la confrontación abierta de las patronales agropecuarias durante el período 2008-2015 (Bona, 2019).

En lo que respecta a la ganadería, si bien los precios relativos de posconvertibilidad generaron un incentivo que permitió recuperar las existencias bovinas (después de un largo proceso de declive desde los años 80 ) durante el período 2002-2007, la sequía de 2008/9 se expresó en una elevada liquidación de vientres. Las políticas de precios regulados en un contexto de expansión del consumo local de carne (en el marco de una economía en plena expansión) generaron una reducción de la oferta bovina y una caída de la rentabilidad (Vértiz, 2015). Asimismo, se evidenciaron las ventajas de una agricultura de alto rendimiento, dado que el paquete tecnológico que posibilitaba el aumento de la siembra de soja en zonas ganaderas generó mayor expulsión de bovinos (Páez, 2016). Tal es así que hacia 2010 se había perdido el 19\% del ganado, en lo que fue una aguda crisis sectorial (Secretaría de Agricultura, Ganadería y Pesca, 2018). De este modo, desaparecieron muchos pequeños productores y, ratificando tendencias precedentes, creció el poder de los grandes frigoríficos en este período (Grimaldi, 2018).

En síntesis, el sector primario exportador había acumulado una serie de grandes transformaciones desde mediados de la década del 90 que imprimieron grandes cambios en el mapa agroganadero del país. La expansión de los cultivos transgénicos, particularmente la soja, desplazó cultivos tradicionales y ganadería y, desde el año 2012, se verificó una tendencia a la reducción de los precios internacionales que afectó al sector en general. Al mismo tiempo, un conjunto de medidas fiscales, monetarias y comerciales se abocaron al «desenganche» de precios locales de los internacionales (para evitar aumentos de la canasta básica ${ }^{3}$ ) y la recaudación aduanera.

La llegada a la presidencia de Mauricio Macri en diciembre de 2015 imprimiría importantes cambios en las políticas económicas en Argentina al regresar a la lógica del patrón de acumulación de la valorización financiera (Basualdo, 2017). El elenco de gobierno consideraba que había un estancamiento justamente en el terreno donde Argentina cuenta con ventajas competitivas en el mercado mundial. En este contexto, uno de sus ejes de campaña había sido la promesa de eliminación de derechos de exportación para el sector primario exportador, así como controles, permisos, cupos, reglamentaciones, etc., para transformar al país en un «supermercado del mundo», incrementando las exportaciones (López y Pascuini, 2017). Por estas razones, el sector agropecuario patronal asumió una posición de apoyo a las propuestas del nuevo presidente (Bona, 2019). 
Bona, Leandro I Tendencias recientes en los cultivos y la producción ganadera en la provincia de Buenos Aires...

Cuadro 1. Conjunto de medidas de política económica de afectación directa sobre el sector agropecuario en el período 2015-2019

\begin{tabular}{|c|c|}
\hline Medidas & Características \\
\hline $\begin{array}{l}\text { Derechos de } \\
\text { exportación }\end{array}$ & $\begin{array}{l}\text { Eliminación de retenciones (excepto soja: } 30 \% \text { para porotos y } 27 \% \\
\text { para subproductos) entre } 2016 \text { y } 2018 \text {. Desde } 2018 \text {, reincorporación } \\
\text { con límite de } \$ 4 \text { y } \$ 3 \text { por dólar exportado (excepto soja: } 25 \% \text { para po- } \\
\text { rotos y } 23 \% \text { para subproductos) }\end{array}$ \\
\hline $\begin{array}{l}\text { Liquidación de } \\
\text { divisas }\end{array}$ & $\begin{array}{l}\text { Eximición de la obligatoriedad de liquidación de divisas (hasta fines de } \\
\text { 2019) }\end{array}$ \\
\hline $\begin{array}{l}\text { Permisos de } \\
\text { exportación }\end{array}$ & $\begin{array}{l}\text { Eliminación del Registro de Operaciones de Exportación (ROE) rojo } \\
\text { (carne), verde (granos) y blanco (leche) }\end{array}$ \\
\hline Reintegros & Aumento de los reintegros a las exportaciones de carne vacuna \\
\hline Tipo de cambio & $\begin{array}{l}\text { Devaluaciones en diciembre de } 2015 \text { y durante } 2018 \text { y 2019. Las mis- } \\
\text { mas transfieren, vía precios, ingresos desde los perceptores de ingre- } \\
\text { sos fijos (asalariados/as y jubilados/as) hacia los de ingresos móviles } \\
\text { (exportadores)노․ }\end{array}$ \\
\hline
\end{tabular}

Fuente: Elaboración propia en base a datos de Boletín Oficial, BCRA e INDEC.

En este contexto, además de colocar en la cartera de Agroindustria a referentes de las patronales agropecuarias representantes de los/as terratenientes de mayor tamaño (R. Buryaile de CRA primero y L. Etchevere de SRA después $\underline{5}$ ), desde el punto de vista cambiario se ejecutó una devaluación de la moneda del orden del $30 \%$, complementado con la decisión de disminución a cero de derechos de exportación a través del Decreto 133 de diciembre de 2015. Esta reducción de las retenciones fue amplia: solo quedó gravada la soja (30\% para porotos y $27 \%$ para subproductos) (Cuadro 1 ). En sus considerandos, el decreto señalaba:

Que el Estado Nacional está decidido a implementar medidas efectivas tendientes a revertir los indicadores negativos de la economía argentina, incluyendo acciones concretas destinadas a superar la crisis agropecuaria y reactivar al sector, eliminando las trabas y restricciones que hoy limitan su capacidad, al tiempo que se favorece el cuidado del capital natural de nuestros suelos (Decreto 133/2015).

Señalaba que el área sembrada había caído (en particular aquella dedicada a trigo y maíz), así como las exportaciones regionales y de carnes, y 
era necesario relanzar las ventas externas del país. Por ende, se pretendía transferir ingresos al sector primario exportador y, a su vez, recuperar la producción de cultivos y ganadería desplazados por la soja. Esta transferencia de ingresos (vía tipo de cambio y quita de retenciones, que generaron un aumento de los precios, particularmente de alimentos) repercutió negativamente sobre el salario, que registró la mayor caída del poder de compra desde 2002 (Basualdo, 2017).

Desde el punto de vista sectorial, se desreguló el comercio exterior al eliminar las declaraciones juradas de percepción de divisas y posteriormente la obligatoriedad de liquidación de las mismas-6. Entre 2016 y 2017 se eliminaron los permisos para ventas al extranjero (ROE) de granos, carnes y leches. Los exportadores de carne vacuna se vieron beneficiados por la elevación de los reintegros para exportaciones, lo que se complementó con mayores de demandas de Rusia y China (Ministerio de Agroindustria, 2018).

Sin embargo, las políticas de retenciones fueron mutando durante este período en el marco de la crisis económica y las necesidades de financiamiento del Estado nacional. Mientras que sobre la soja las retenciones no se eliminaron en 2016 y 2017, en 2018 comenzaron a reducirse paulatinamente (a razón de 0,5 puntos porcentuales por mes). La crisis de este modelo de valorización financiera desde abril de 2018, que se expresó en corrida cambiaria, devaluación y recesión (Panigo y otros, 2019), se completó con un acuerdo con el Fondo Monetario Internacional para recibir un préstamo del orden de los USD 44.300 millones, que incluía condiciones sobre el plano fiscal, comercial y monetario (Bona, 2021). Para ello se exigía una reducción del déficit fiscal del gobierno nacional, por lo que las retenciones regresaron.

En septiembre se recolocaron derechos de exportación para este cultivo del $18 \%$ (fijo) más el $12 \%$ (con límite de $\$ 4$ por dólar para porotos y $\$ 3$ para subproductos). En el caso de los restantes cereales y oleaginosas y carnes, se establecieron en $12 \%$ con límite de $\$ 4$ por dólar para bienes primarios y $\$ 3$ para subproductos. Al tipo de cambio vigente en esa fecha, se trataba de cargas del orden del 10 y $8 \%$, aunque con el correr de la devaluación de la moneda en 2019 irían perdiendo protagonismo hasta llegar al 5 y $7 \%$ (con la mencionada excepción de la soja, que terminó 2019 con una carga del 25 y $23 \%$ respectivamente). El retorno de las retenciones se produjo en el mismo año donde una gran sequía afectó la producción primaria de manera sustancial, en especial en parte de la zona núcleo pampeana (Ministerio de Agroindustria, 2020).

Por su parte, si bien en el plano normativo es relativamente menor el impacto que tienen las políticas subnacionales sobre el sector primario exportador, 
el gobierno de la provincia de Buenos Aires habilitó mayores créditos al sector, particularmente en moneda extranjera en 2016 y 2017 (Observatorio de Bioeconomía, 2019) y dictaminó la emergencia agropecuaria en 2018 para eximir del pago de impuestos a veintisiete distritos bonaerenses ese año (Decreto 5282/18 del Ministerio de Economía).

En este contexto, la evolución de la producción sectorial no resultó equitativa entre las distintas regiones bonaerenses, sino que mostró las diferencias en las estrategias desplegadas según las condiciones climáticas del territorio de la provincia de Buenos Aires.

\section{Las regiones productivas bonaerenses y el impacto de los cambios recientes}

El análisis se concentra en la provincia de Buenos Aires dada su relevancia en la producción agroganadera del país, pues aquí se ubica aproximadamente un tercio del total de la superficie implantada de cereales, forrajes y oleaginosas, así como el $37 \%$ de las cabezas de ganado bovino.

Cuadro 2. Participación de la provincia en el producto bruto interno y sectores seleccionados del país. Año 2018

\begin{tabular}{l|l}
\hline PBG & $36 \%$ \\
\hline Agricultura, ganadería, silvicultura y pesca & $38 \%$ \\
\hline Ganado bovino & $37 \%$ \\
\hline Cereales & $34 \%$ \\
\hline Oleaginosas & $31 \%$ \\
\hline Forrajeras & $34 \%$ \\
\hline Exportaciones de cereales & $44 \%$ \\
\hline Exportaciones de oleaginosas & $32 \%$ \\
\hline Exportaciones de carne bovina & $53 \%$ \\
\hline
\end{tabular}

Fuente: Elaboración propia en base a datos del Censo Nacional Agropecuario (2018), Ministerio de Economía de la provincia, Observatorio de Bioeconomía (PBA) e INDEC.

La delimitación productiva regional para la provincia de Buenos Aires que se realiza en este trabajo aprovecha el enfoque utilizado por el Gobierno de la Provincia de Buenos Aires en 2011, donde se establecen siete áreas 
(excluyendo la Región Metropolitana de Buenos Aires). Esta metodología se empleó también en Basualdo y otros (2019), y guarda relación con regionalizaciones productivas precedentes que identifican las zonas agronómicas por excelencia de la provincia (Secretaría de Agricultura, Ganadería y Pesca, 1996). Sin embargo, no se concentra solo en aspectos agronómicos sino además en otros criterios, como los poblacionales (no más de 1,4 millones de habitantes), geográficos (distritos colindantes), de cantidad de municipios (entre diez y veinticinco) y productivos (por composición sectorial y de cadenas de valor afines) -

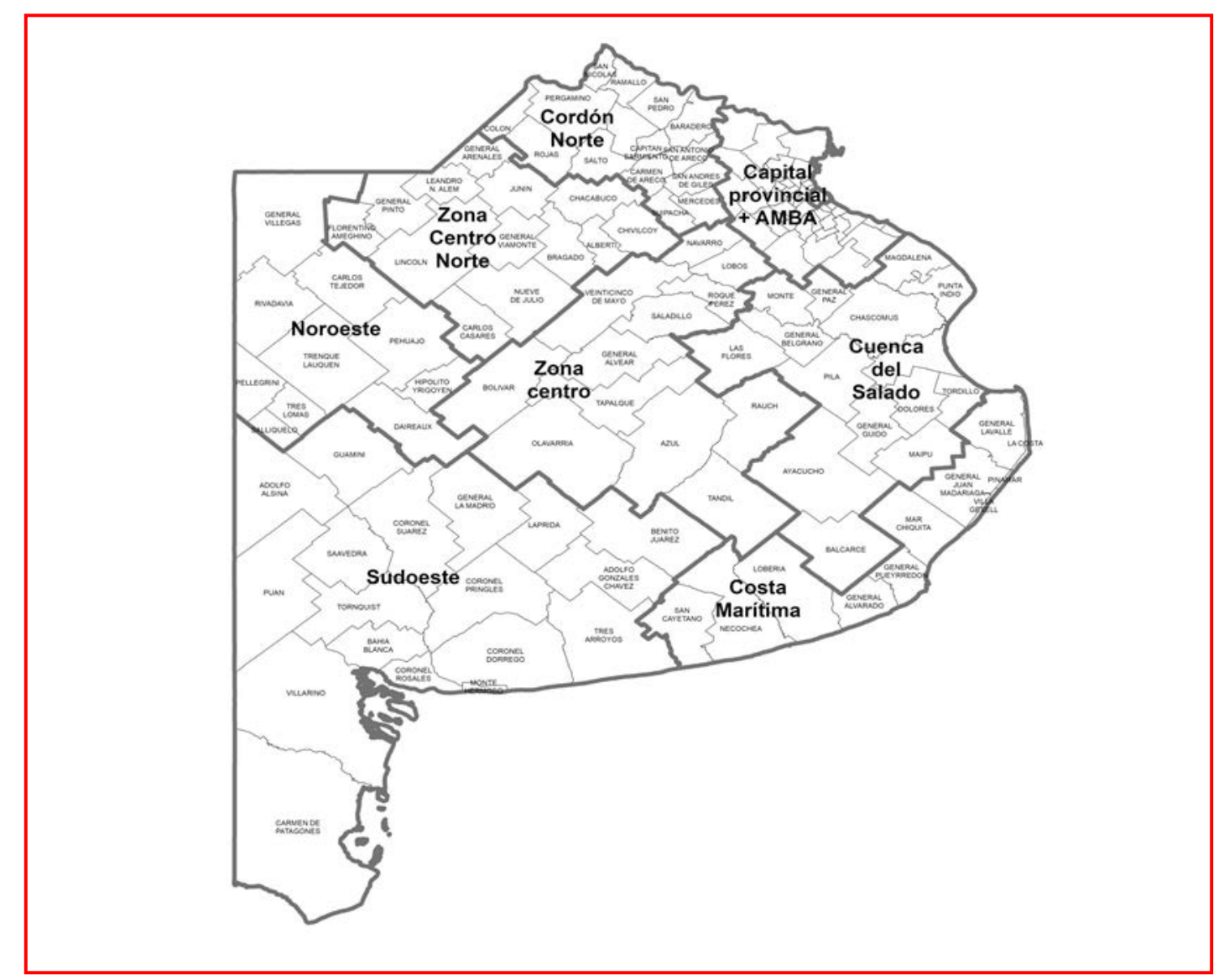

Gráfico 2. La provincia de Buenos Aires según regiones productivas

Fuente: Basualdo, Manzanelli y Bona (2019).

A continuación, se presentan las características salientes de las regiones bonaerenses discriminadas y los principales cambios allí ocurridos materia de producción primaria en años recientes. 


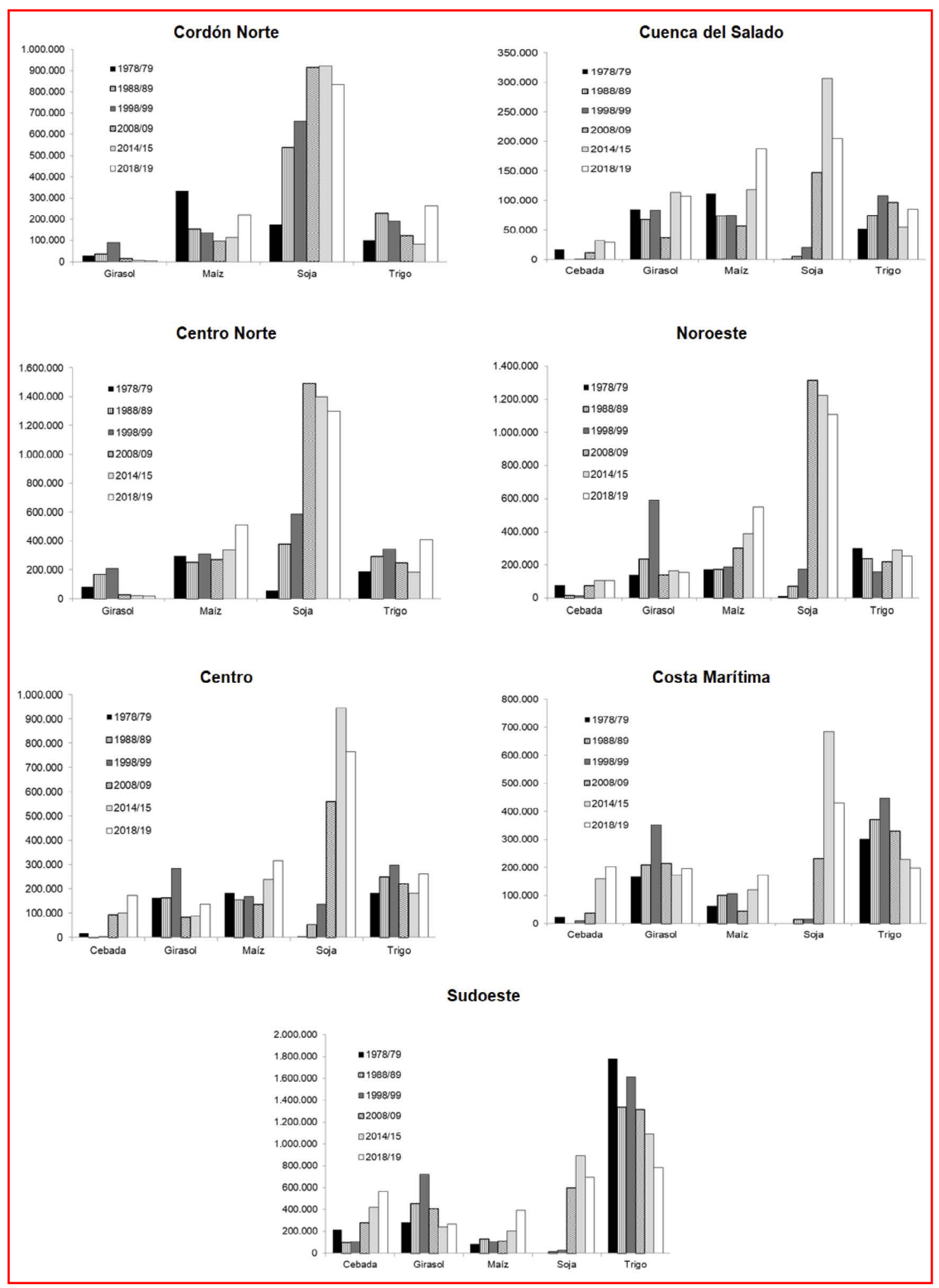

Gráfico 3. Evolución de la superficie sembrada de girasol, maíz, soja y trigo de los cultivos en las regiones bonaerenses. Campañas 1978/79, 1998/99, 2008/09, 2014/15 y 2018/19 (hectáreas)

Fuente: Elaboración propia en base a datos de Estimaciones Agrícolas (Ministerio de Agricultura, Ganadería y Pesca). 


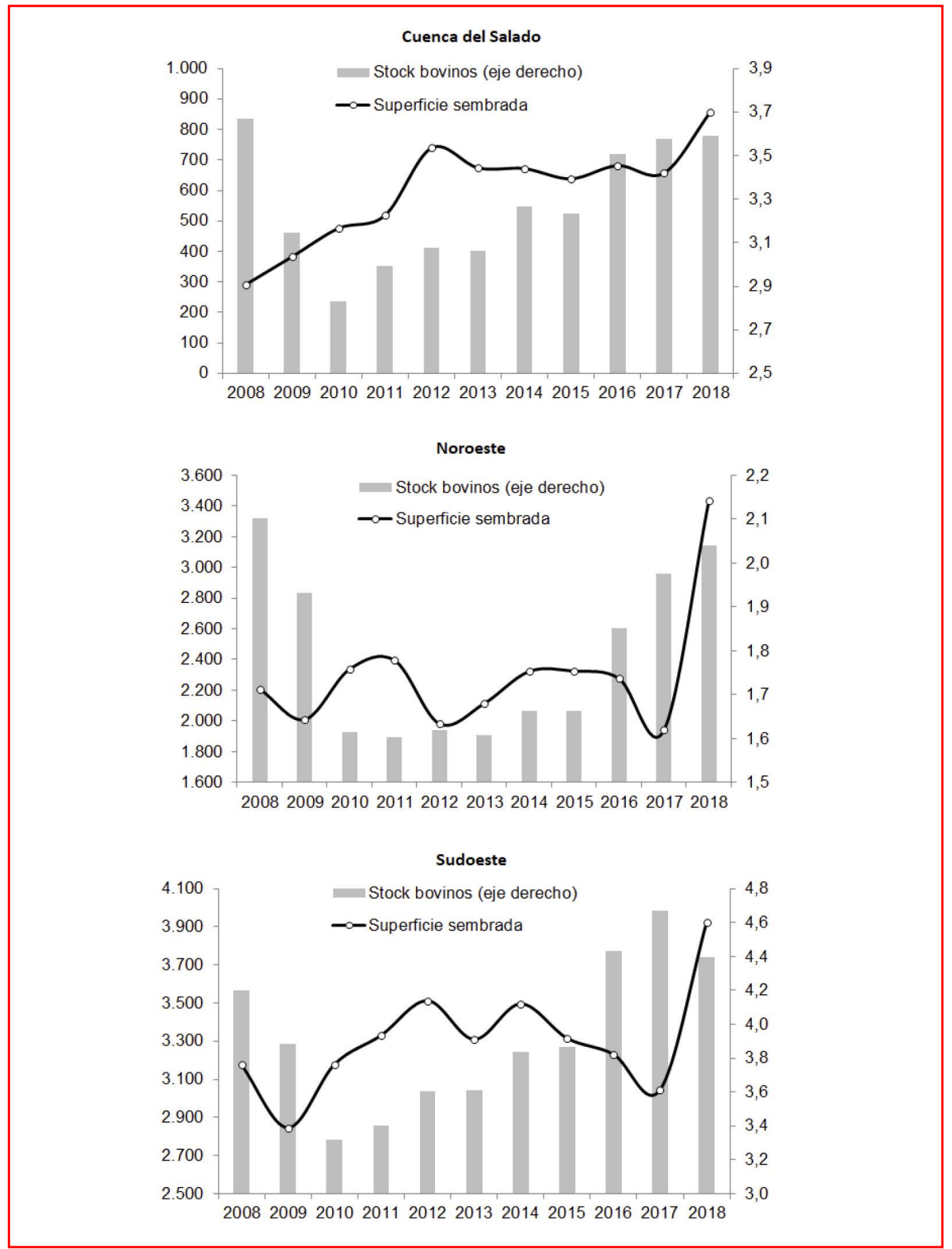

Gráfico 4. Evolución de la superficie sembrada (principales cultivos-miles de ha) y el stock de bovinos (millones). Años 2008-2018

Fuente: Elaboración propia en base a datos de Estimaciones Agrícolas (Ministerio de Agricultura, Ganadería y Pesca) y SENASA. 


\section{a. Cordón Norte}

El Cordón Norte de la provincia de Buenos Aires integra el núcleo agropecuario pampeano y goza de los rendimientos más elevados del mundo, especialmente en los municipios de Rojas, Salto y Pergamino. Gracias a ello, ha registrado una importante capacidad de adaptación al contexto, en el marco de una producción concentrada en la demanda mundial.

En la zona norte de esta región se advierten los mayores niveles de productividad del suelo, y por ello el paradigma sojero tuvo una impronta particular, ya que su preponderancia se remonta a décadas anteriores a la de 1990. Hasta la década del 70 esta era una zona tradicionalmente maicera, seguida por la producción de trigo, y contaba con una importante diversificación de cultivos tales como sorgo, avena, cebada y papa, entre otros. Pero la expansión de la siembra de soja no transgénica comenzó a tomar cuerpo desde ese momento, cuando la demanda mundial empezó a crecer, y se volvió predominante desde la campaña 1983/84; allí comenzó su combinación con el trigo. A partir de entonces, la superficie sembrada de soja superó a los otros cultivos y desde fines de los años 80 la soja ocupa más del $50 \%$ de la superficie sembrada en la región, gracias a sus condiciones climáticas favorables. Dicha tendencia se sostuvo, pero la incorporación del paquete transgénico desde 1996 aceleró la trayectoria expansiva de esta oleaginosa en el Cordón Norte, donde los restantes cultivos pasaron a resultar absolutamente marginales en las primeras décadas del siglo XXI.

El fenómeno conllevó alteraciones ambientales de peso. En los últimos lustros se asistió a una muy escasa o nula rotación de cultivos: entre las campañas 2002/03 y 2014/15 tres cuartas partes del Cordón Norte fueron implantadas con soja. Es aquí donde se concretó el epicentro de la tendencia al monocultivo ajustada a una demanda externa creciente durante los primeros años del siglo XXI. A su vez, la superficie sembrada de los principales cultivos se duplicó entre los años 70 y la campaña 2018/19, a partir de mayor aprovechamiento del suelo y el desplazamiento del ganado vacuno, que pasó a ocupar un lugar absolutamente marginal. Por lo tanto, aquí se advierte que más allá de los cambios en la economía política del período 2002-2015, en ese período no se alteró sino que se profundizó el modelo de negocios del monocultivo sojero, procurando alentarlo y, de ese modo, que el Estado capte mayores niveles de renta.

Más allá de su expansión, la participación de esta región en la producción provincial de soja cayó a un quinto del total bonaerense en las últimas campañas (representaba más de la mitad en los años 80), debido a que el incremento de los rendimientos por hectárea y las nuevas tecnologías llevaron la 
producción de soja a muchos partidos donde era, otrora, inviable. De todas formas, el maíz y el trigo no se extinguieron, pues esta región aporta el 15,1\% y el $12,5 \%$ del total provincial (Cuello, 2016), aunque el girasol sí se contrajo a niveles casi nulos. En síntesis, entre 1970 y 2015, el Cordón Norte se transformó en el eje del paradigma sojero y lo hizo en desmedro principalmente del girasol, del ganado bovino y, parcialmente, del trigo.

Las medidas implementadas en 2015-2019, en particular la eliminación de los derechos de exportación sobre todos los cultivos (con excepción de soja), permitieron una mejora en la rentabilidad de otras siembras, lo que redundó en importantes cambios en la composición de la superficie sembrada: le cebada, el maíz y el trigo duplicaron las hectáreas ocupadas, ocupando las 95.000 hectáreas que perdieron la soja, el sorgo y el girasol y los restantes cultivos (Ministerio de Agricultura, 2020).

\section{b. Centro Norte}

La región del Centro Norte integra, como en el caso del Cordón Norte, el entramado agrícola productivo más importante del país. Se destaca por su capacidad de producción de soja, maíz y trigo, con un nivel de producción que representa entre el $20 \%$ y el $26 \%$ de esos cultivos en el total provincial. Dada su elevada calidad y fertilidad del suelo, el destino principal de esta producción es el mercado mundial; por estos motivos, el ganado bovino tiene una escasa gravitación debido a que se trata de una zona eminentemente agrícola (no obstante, es relevante la industria láctea en el partido 9 de Julio).

Junto con el Cordón Norte esta región resulta en una de las mayores productoras de estos recursos del país: de cada cuatro toneladas de soja que se producen en la provincia, una proviene del Centro Norte. Lo propio cabe para la producción de maíz ( $25 \%$ ), en tanto que el trigo aporta un poco menos pero igualmente trascendente para la producción provincial $(20,8 \%)$. El cuadro de situación es muy similar al de la región Cordón Norte, aunque la superficie destinada a soja aquí era muy marginal desde los años 70 y tuvo un crecimiento singular hacia los años 80 y 90 . Asimismo, el girasol ha perdido relevancia desde fines de los años 90, y mientras el maíz permaneció estable, el trigo tuvo una caída entre 1998/99 y 20014/15. Esta dinámica expansiva del uso del suelo agrícola corrió a cuenta entonces del ganado bovino, en lo que expresa una competencia por el uso del suelo donde la agricultura de exportación desplazó a la carne (Páez, 2016), un sector de mayores requerimientos de mano de obra. El fenómeno ilustra la escasa planificación estratégica del sector agrícola durante los gobiernos kirchneristas, en una tensión permanente entre generación de divisas para 
afrontar la restricción externa y políticas sustentables a largo plazo (Reboratti, 2010).

Los cambios inaugurados por la gestión de Cambiemos produjeron aquí resultados similares a los del Cordón Norte, pues después de años de retroceso, el trigo duplicó las hectáreas sembradas entre 2014/15 y 2018/19. El maíz, que había ocupado una porción relativamente estable de hectáreas sembradas hasta 2014/15, también logró una recuperación significativa y se aproximó a las 600.000 hectáreas sembradas en 2018/19. Nuevamente, estas transformaciones implicaron el desplazamiento (parcial) de la soja, junto con otros cultivos. Como dato interesante, dado que en esta zona la productividad decrece en relación con la zona núcleo (particularmente al sur de la región), la cebada, a diferencia del proceso de recuperación allí registrado, sufrió una merma.

Adicionalmente, esta región presenta una subárea donde la producción lechera cobra mayor protagonismo, en particular en los partidos 9 de Julio, Lincoln, Carlos Casares y General Pinto. Pero la actividad láctea no fue beneficiada con políticas específicas (más allá del retiro del ROE blanco y la eliminación de retenciones): registró las consecuencias de un mercado interno en retroceso (el consumo anual per cápita de leche cayó un $18 \%$ entre 2015 y 2019) y la falta de dinamismo exportador, y el sector continuó el proceso de concentración de años anteriores (Grimaldi, 2018). En este sector, entonces, se verificaron las consecuencias del aumento de los costos de insumos como la energía y el transporte durante 2015-2019, pues en el país desaparecieron unos 780 tambos por año en 2016 y 2017 (Rodríguez, 2018), y la producción total de leche se contrajo un $15 \%$ entre 2015 y 2019 (Ministerio de Agricultura, 2020). En el patrón de acumulación de la valorización financiera del período 2015-2019, los sectores primarios beneficiados se concentraron en la gran producción agrícola y ganadera, pero no en las unidades de negocios menos dinámicas.

\section{c. Centro}

La región Centro tiene características particulares, pues exhibe dos zonas marcadamente distintas: por un lado, el área lindera a la región metropolitana (Lobos, Navarro, Roque Pérez, Saladillo y 25 de Mayo), con menor peso poblacional y una fuerte centralidad de la actividad agropecuaria, y luego, en la zona sur (en el nodo conformado por Tandil, Azul, Olavarría), se incorpora mayor dotación de actividades secundarias y terciarias, dado que se centralizan las ventas de insumos y materiales vinculados principalmente a la producción agropecuaria y minera de rocas en Olavarría. 
La producción agrícola se concentra en los principales cultivos (soja, maíz y trigo), aunque se destacan con mayor relevancia que en los casos del norte las producciones de cebada cervecera y girasol. Se caracteriza por una alta participación en cereales y oleaginosas, pues poco más de una de cada diez toneladas de soja que produce la provincia proviene de la región Centro. La proporción es un poco más alta en el maíz $(13,2 \%)$ y la cebada cervecera $(14,3 \%)$ y levemente inferior en el girasol $(11,8 \%$ ) y el trigo $(9,9 \%)$.

Asimismo, el ganado vacuno ha tenido tradicionalmente una importante gravitación en la región: Olavarría y Azul son dos de los tres partidos con mayores existencias bovinas de la provincia.

También aquí se replican los cambios tecnoproductivos ocurridos bajo la implementación de los paquetes tecnológicos transgénicos. Mientras hasta los años 90 la región ocupaba muchas hectáreas en ganadería, la actividad fue crecientemente desplazada por la agricultura y «obligada» a incrementar el proceso de engorde a corral. Asimismo, existía una preponderancia de maíz, trigo y girasol durante el siglo XX, que pasó a segundo plano debido a la extensión de la soja, aunque en este caso el salto se dio en los años 2000. Solo en diez años, entre las campañas 2008/9 y 2018/19, la superficie sembrada con los seis principales cultivos (cebada, girasol, maíz, soja, sorgo y trigo) creció un $50 \%$, intensificando el uso del suelo disponible para agricultura y ratificando que las políticas sectoriales durante los gobiernos kirchneristas no parecen haber tenido como propósito equilibrar las rentabilidades relativas entre las distintas producciones agropecuarias.

Las medidas implementadas en el período 2015-2019 tuvieron un impacto positivo en la recuperación de la presencia de maíz, trigo, girasol y cebada. Mientras 182.000 hectáreas fueron «liberadas por soja» entre las campañas $2014 / 15$ y 2018/19, las mismas fueron ocupadas por estos tres cultivos, en el orden de las 70.000 cada una. De esta manera, una zona eminentemente ganadera y con presencia de trigo, maíz y girasol pasó a ser un núcleo sojero, con mayor diversificación reciente hacia otros de los cultivos principales, redefiniendo sus características históricas.

\section{d. Cuenca del Salado}

La Cuenca del Salado presenta una tradición distinta, pues aquí la producción ganadera es una de las más relevantes del país y la agricultura ha ocupado un papel menos destacado. Se trata de un sector paradigmático en materia de ganadería de cría, con una larga historia debido a las condiciones de sus suelos (Ministerio de Agroindustria, 2018). El stock ganadero cuenta con 3,6 millones de cabezas (el 19,2\% del stock provincial), en una proporción de 
aproximadamente diez bovinos por habitante, lo cual es una muy elevada proporción incluso para la provincia de Buenos Aires.

Uno de los déficits históricos de la región, a pesar de su abundancia ganadera, ha sido su escaso procesamiento. Sin embargo, desde hace quince años se ha avanzado desde la simple cría hacia la recría y terminación de terneros, dando lentos pasos hacia la culminación del ciclo ganadero completo (especialmente en Ayacucho, General Belgrano y Tordillo). Esto indica que se ha producido cierta competencia por el uso del suelo entre estas actividades, aunque sigue predominando fuertemente la cría ya que su coeficiente de orientación productivo ronda el valor de 0,2 (es decir, un muy bajo peso de novillo o novillito por vaca, lo que pone en evidencia el predominio de la actividad de cría) (INTA, 2015)ํㅗ. El forraje es mayormente natural, aunque en los últimos tiempos el sorgo se ha implementado para suplementar el ciclo ganadero.

Hasta el siglo XXI, los cultivos predominantes eran trigo, girasol y maíz, lo que cambió drásticamente en los años 2000, pues en la campaña 2008/9 la soja tomó el liderazgo, una situación que se profundizó hacia 2014/15.

Uno de los fenómenos relativamente recientes que la Cuenca del Salado pone de relieve es la competencia por el uso del suelo. Ello se expresa en la selección, por parte de propietarios y arrendatarios, del destino que se da a las tierras disponibles en una zona tradicionalmente dedicada al ganado de cría de terneros. La creciente expansión de la agricultura, ocupando las zonas más elevadas (lomas) y, por ende, no inundables, ha sido alentada por el paradigma sojero (hasta 2015) y recientemente maicero. Los principales cuatro cultivos de exportación han crecido significativamente en cuanto a la superficie sembrada, superando las 600.000 hectáreas. Estos cambios obedecieron a las mencionadas alteraciones en las rentabilidades relativas de los cultivos por efectos de la eliminación de derechos de exportación de productos primarios (con excepción de la soja) desde diciembre de 2015 (BCR, 2018). En definitiva, hubo fuertes desplazamientos de soja por maíz, aunque también por trigo y, en menor medida, girasol.

Como se observa en el gráfico respectivo, después de la crisis del sector cárnico en el período 2008-2010 en la que se constató una importante liquidación de vientres (especialmente en la Cuenca del Salado, donde disminuyó el nivel de vacunos en 800.000 cabezas), el stock ganadero comenzó a recuperarse desde 2011 por efecto de una recomposición en los márgenes, que llegaron a niveles particularmente elevados en 2011, 2012 y 2015 (Ministerio de Agroindustria, 2018). La crisis del sector ganadero hacia 2009 obligó en su momento a revisar las políticas de retenciones y permisos para la producción de carnes 
(Vértiz, 2015). El gran salto subsiguiente, el del bienio 2016-2017, se produjo por una combinación de nuevos factores: al aliento en la rentabilidad de 2015 (que impacta en 2016) se le agregaron mejores perspectivas para el sector al calor de la demanda externa de socios como China y Rusia (IPCVA, 2018).

En el marco de la citada competencia por el uso del suelo, se ha constatado que desde 2010 se registra un crecimiento tanto del stock ganadero como de la superficie sembrada, lo que indica que los animales se encuentran distribuidos en menos tierras. Ello dio lugar al aumento de las existencias de feed-lots, que permiten aumentar el engorde sin ocupar amplias extensiones de tierras (Maresca, 2018).

\section{e. Noroeste}

La Región Noroeste está integrada por apenas diez partidos que tienen una baja densidad poblacional, aunque su importancia en la provincia reside en que se trata de zona clave en materia agropecuaria debido a la fertilidad de sus tierras. El predominio de la producción agrícola tiene asiento en los principales cultivos pampeanos (soja, maíz, trigo y girasol), con una intensa dinámica asociada a la siembra directa en el marco del paradigma sojero de los últimos años. Bajo estas circunstancias, fue modificando paulatinamente su tradición triguera por el crecimiento del girasol en los años 90 para luego transformarse en una de las principales productoras de soja en el marco de la posconvertibilidad.

Su contribución a la producción agrícola es sumamente significativa ya que en una superficie que representa el $11,2 \%$ de la superficie provincial se obtienen entre un quinto y un cuarto del total de su producción en el territorio bonaerense de tales cultivos. Al cabo de casi dos décadas (2000-2018) prácticamente se duplicó la superficie sembrada, lo que ha desplazado la actividad ganadera, perdiéndose de esa manera buena parte de la rotación agrícola-ganadera que era tradicional hasta hace algunas décadas.

Como área que pertenece al primer anillo que circunvala la zona núcleo ligada al paradigma sojero desde los años 2000, se constituye en una región clave como modelo de desarrollo del agronegocio vinculado a la producción transgénica. Su caso es paradigmático acerca del veloz tránsito que se produjo en las últimas décadas desde la ganadería hacia la agricultura, y luego, dentro de esta última, desde el trigo y el girasol hacia la producción de soja y de maíz. La información proporcionada por el gráfico respectivo permite advertir la evolución de la superficie sembrada en la región Noroeste de los cuatro principales cultivos. Allí se pone de relieve que hasta mediados de los años 90 prevalecían ampliamente el trigo, el maíz y el girasol. La superficie sembrada con los cuatro cultivos entre las campañas 1969/1970 y 1994/1995 
fue en promedio de 684.000 hectáreas por año, con un reemplazo considerable de trigo por girasol desde mediados de los años 80 .

Lo notable es que desde la irrupción del paquete tecnológico transgénico en 1996, se produce un salto exponencial de la siembra de soja, potenciado luego de la crisis económica de 2001/02, lo que lleva a este cultivo a superar las 1.300.000 hectáreas sembradas en la campaña 2007/2008. En promedio, entre las campañas de 2007/2008 y 2017/2018 la superficie sembrada fue de 1.984.000 millones, tres veces más que el promedio 1969/1970-1994/1995.

La producción líder en términos de su volumen físico (toneladas) pasó de ser la soja en 2015/16 al maíz en 2017/18, en el marco del sostenimiento de retenciones sobre la primera y la eliminación de las mismas sobre el resto, aunque en términos de la superficie sembrada el predominio de la soja es sustantivo. La producción de girasol y especialmente el trigo crecieron significativamente en la campaña 2016/17 (17,3\% y 94,4\%, respectivamente), al tiempo que la soja cayó $24,2 \%$. Los avatares climáticos derrumbaron la producción en la campaña 2017/18 en todos los cultivos, con excepción del maíz. En efecto, el inédito crecimiento de la producción sojera conllevó el desplazamiento de otros cultivos y de la ganadería.

En materia de ganadería hay variantes, ya que si bien se trata de una zona históricamente de invernada, actualmente solo es practicada de manera significativa en cuatro partidos (Rivadavia, Pellegrini, Salliqueló y Tres Lomas), mientras que en Trenque Lauquen, General Villegas, Daireaux y Carlos Tejedor predomina el ciclo completo. Este último se desarrolla con modelos de media y alta producción que rotan trigo, girasol, soja de primera y sorgo o maíz, con dotaciones ganaderas que ocupan poco más de la mitad de los campos disponibles (Ministerio de Agroindustria, 2018).

Los cambios normativos implementados desde 2015 tuvieron un alto impacto. A diferencia de otras regiones analizadas previamente, aquí la recuperación del stock bovino fue moderada entre 2012 y 2015, pero resultó mucho mayor en 2016-2019. Las existencias ganaderas crecieron prácticamente un $50 \%$ entre 2015 y 2018 (Gráfico Noroeste), y es esta una zona donde la tendencia al uso del engorde a corral modificó la modalidad histórica de invernada en algunas regiones.

\section{f. Costa marítima}

La Costa marítima desde el punto de vista productivo presenta dos áreas bien diferenciadas: el turismo y las actividades primarias. En el caso de la ganadería de cría, esta ha sido tradicional en la zona de la Cuenca del Salado que pertenece a esta región, es decir, el sector noreste de la Costa marítima (Mar 
Chiquita, General Madariaga, General Lavalle), así como en el sur (Lobería). La distribución de animales resulta sumamente desigual, acorde a las condiciones del suelo. Entre Mar Chiquita, Gral. Madariaga, Lobería, Gral. Lavalle y Necochea concentran el $84 \%$ del total de ganado bovino, especialmente dedicado a la cría (vacas y terneros), es decir, con escasa gravitación del ciclo completo.

Como en otros casos, el paradigma de los cultivos de exportación se impuso en años recientes al incrementar la superficie cultivada (la misma aumentó un $50 \%$ entre 2008 y 2014), lo que se revirtió solo parcialmente en 2016/18, gracias al incremento del stock bovino como resultado principalmente de la demanda mundial y también por las políticas de estímulo al sector que incidieron en la estructura de precios relativos (Gráfico Costa Marítima).

La competencia por el uso del suelo entre agricultura y ganadería se expresa en el incremento no solo de la soja y el maíz, sino además en los incrementos de las cosechas fina (trigo) y gruesa (girasol). Precisamente estos dos cultivos son abundantes en la Costa marítima y se vieron beneficiados por la demanda mundial de alimentos y la quita de retenciones a las exportaciones desde diciembre de 2015. De hecho, mientras en 2015/16 la soja lideraba la producción, seguida de lejos por maíz, trigo y girasol, en 2017/18 el ranking pasó a estar encabezado por el maíz, y la soja ocupó el tercer escalón, detrás del trigo. La sequía de la campaña 2017/18 afectó a la zona núcleo de la provincia (fundamentalmente Cordón y Centro Norte del territorio bonaerense) y no a esta región, por lo que los rindes tuvieron un alza entre 2015 y 2018. Parte la caída de la producción de soja en la campaña 2016/17 obedeció al aumento de superficie destinada a la ganadería, además de los mencionados incrementos en las siembras de los otros cultivos.

\section{g. Sudoeste}

La Región Sudoeste se constituye en una de las más extensas del territorio bonaerense y presenta condiciones climáticas relativamente diversas, con una zona de características patagónicas en el sur y mayor fertilidad del suelo hacia el norte de la misma. La actividad agrícola-ganadera es preponderante a partir del desarrollo de la ganadería de invernada, sumada a la cosecha de trigo, girasol y cebada cervecera. La horticultura resulta fundamental en el sur de la región gracias a la siembra por regadío. Tradicionalmente la presencia de ganado vacuno ha sido la de mayor ocupación de tierras disponibles, más allá de cierto avance de los principales cultivos en las últimas décadas. El ganado bovino supera los 4,6 millones de cabezas, lo cual es equivalente al $25 \%$ del total bonaerense.

Más allá del predominio de la cría, existen establecimientos en los partidos que se ubican al sur del Río Colorado que realizan el ciclo completo. Estas 
unidades productivas que se basan en la ganadería tienen entre 500 y 1.000 hectáreas, se sustentan en alimentos naturales (pastizales) y en terrenos que, en muchos casos, no son aptos para la agricultura debido a la frecuencia de heladas, vientos fuertes y escasas lluvias. Los campos de cría no son inferiores a las 2.000 hectáreas y la productividad es relativamente baja (Secretaría de Agricultura, Ganadería y Pesca, 2018).

Cabe destacar que en la actualidad crecieron los cultivos de cosechas que otrora eran ajenas a la región. Ello no está disociado, del mismo modo que en otras regiones, del paradigma sojero instalado desde mediados de los años 90 que tendió a desplazar a la ganadería a favor de los cultivos agrícolas. Este desplazamiento de la ganadería cobró una magnitud superior entre 2008 y 2010 en el marco de la sequía y la mejora relativa de las rentabilidades agrícolas, cuando la liquidación de vientres implicó una pérdida de alrededor de 900.000 animales. Sin embargo, dicho proceso se modificó a partir de 2011 ya que desde allí el stock bovino se fue recuperando paulatinamente, con un crecimiento significativo en el bienio 2016-2017, cuando la mejora en las condiciones del sector y el incremento de la demanda externa de carne argentina le otorgaron mayores estímulos para su expansión. De esta manera, en 2017 el stock ganadero ya había superado las existencias de 2008, con unas 4,6 millones de cabezas en pie (Gráfico 4).

La agricultura, por su parte, ha sufrido significativas modificaciones respondiendo a los cambios en las rentabilidades relativas entre cultivos. En una zona tradicionalmente dedicada a la cosecha fina (trigo), con importantes rindes en girasol, desde mediados del decenio de 1990 se produjo un incremento significativo de la soja, que llegó a ocupar el segundo lugar en toneladas producidas en los años 2000 (Ministerio de Agroindustria, 2018). En este contexto y desde $2008 / 9$, la importante caída verificada en la producción de trigo fue compensada con incrementos en soja y cebada cervecera, que aumentaron en el marco de la citada liquidación de vientres. Una vez producido ese fenómeno, en los últimos tres años las cosechas de trigo, maíz y girasol crecieron desplazando especialmente a la soja, único cultivo que preservó las retenciones en el período 2016-2017.

Por lo tanto, las políticas de 2015-2019 generaron importantes cambios, pues entre las campañas 2015/16 y 2017/18 la producción de soja cayó un $48 \%$ y la de cebada cervecera un $10 \%$, mientras que la de maíz aumentó un $87 \%$, la de trigo, $63 \%$, y la de girasol, $42 \%$. Ello fue concomitante a una recuperación ganadera muy significativa en 2016 y 2017, lo que indica que esta actividad recuperó terreno en detrimento de los cultivos. 


\section{Evidencias de concentración y los resultados comerciales en la provincia de Buenos Aires}

\section{a. Concentración}

En el marco de las evidencias presentadas en las distintas regiones de la provincia, cabe apuntar que los fenómenos más recientes se registraron bajo proceso de concentración de la tenencia de la tierra, profundizando tendencias ya anotadas desde la década del 90 (Basualdo, 2008). La extensión de las grandes haciendas, las diversas modalidades de propiedad común (sociedades anónimas, fideicomisos, fondos comunes de inversión) y el creciente uso de una tecnología extensiva ratificaron tanto la adquisición como el arrendamiento de tierras por parte de grandes propietarios en el siglo XXI. Este proceso se verificó en los resultados del Censo Nacional Agropecuario 2018, donde:

Por un lado desaparecieron muchas explotaciones, pero al mismo tiempo creció la superficie productiva dedicada a los cultivos anuales. En los últimos 30 años, la superficie implantada se mantuvo en unas 33 millones de hectáreas, pero la proporción de esa superficie dedicada a cultivos anuales como la soja, el trigo y el maíz aumentó de 7,67 a casi 23 millones de hectáreas, en detrimento de otras producciones como las pasturas y las producciones regionales. (...) Quiere decir que es un proceso de concentración, con explotaciones más chicas que se anexan a otras más grandes. El problema es que tenemos más hectáreas en producción y explotaciones de mayor escala, pero menos establecimientos. La tierra no salió de la producción, sino que hay menos gente produciendo. (Repetto, 2019) 
Bona, Leandro I Tendencias recientes en los cultivos y la producción ganadera en la provincia de Buenos Aires...

Cuadro 3. Distribución de explotaciones agropecuarias con límites definidos en la provincia de Buenos Aires. Censos 2002- y 2018 (explotaciones agropecuarias en unidades y hectáreas) y comparaciones porcentuales

\begin{tabular}{|c|c|c|c|c|c|c|c|c|c|c|}
\hline \multirow{2}{*}{$\begin{array}{l}\text { Provincia de } \\
\text { Buenos Aires }\end{array}$} & \multicolumn{2}{|c|}{ Censo 2018} & \multirow{2}{*}{$\begin{array}{c}\% \\
\text { total }\end{array}$} & \multirow{2}{*}{$\begin{array}{c}\% \\
\text { total }\end{array}$} & \multicolumn{2}{|c|}{ Censo 2002} & \multirow{2}{*}{$\begin{array}{c}\% \\
\text { total }\end{array}$} & \multirow{2}{*}{$\begin{array}{c}\% \\
\text { total }\end{array}$} & \multicolumn{2}{|c|}{$2018 / 2002$} \\
\hline & EAP & $\mathrm{Ha}$ & & & EAP & $\mathrm{Ha}$ & & & EAP & $\mathrm{Ha}$ \\
\hline Hasta 5 & 2.926 & 5.664 & & & 2.180 & 6.247 & & & $34 \%$ & $-9 \%$ \\
\hline $5,1-10$ & 659 & 5.146 & & & 1.426 & 11.476 & & & $-54 \%$ & $-55 \%$ \\
\hline $10,1-25$ & 1.278 & 23.588 & & & 2.918 & 52.822 & & & $-56 \%$ & $-55 \%$ \\
\hline $25,1-50$ & 2.194 & 86.672 & $40 \%$ & $0 \%$ & 4.527 & 176.789 & סו כד & $0 \%$ & $-52 \%$ & $-51 \%$ \\
\hline $50,1-100$ & 3.966 & 305.509 & & & 7.017 & 535.580 & & & $-43 \%$ & $-43 \%$ \\
\hline $100,1-200$ & 5.824 & 870.091 & & & 8.827 & 1.309.159 & & & $-34 \%$ & $-34 \%$ \\
\hline $200,1-500$ & 8.575 & 2.825 .669 & & & 11.449 & 3.736 .839 & & & $-25 \%$ & $-24 \%$ \\
\hline $500,1-1.000$ & 5.374 & 3.829 .854 & $49 \%$ & $54 \%$ & 6.433 & 4.548 .669 & $44 \%$ & $59 \%$ & $-16 \%$ & $-16 \%$ \\
\hline $1.000,1-2.500$ & 4.019 & 6.186 .322 & & & 4.588 & 7.011 .887 & & & $-12 \%$ & $-12 \%$ \\
\hline $2.500,1-5.000$ & 1.218 & 4.208 .555 & & & 1.265 & 4.333 .701 & & & $-4 \%$ & $-3 \%$ \\
\hline $5.000,1-7.500$ & 353 & 2.111 .139 & & & 291 & 1.756 .911 & & & $21 \%$ & $20 \%$ \\
\hline $7.500,1-10.000$ & 124 & 1.065 .887 & $5 \%$ & $40 \%$ & 94 & 807.521 & $3 \%$ & $33 \%$ & $32 \%$ & $32 \%$ \\
\hline $10.000,1-20.000$ & 108 & 1.493 .194 & & & 78 & 1.070 .255 & & & $38 \%$ & $40 \%$ \\
\hline 20.000,1 y más & 26 & 734.701 & & & 14 & 430.814 & & & $86 \%$ & $71 \%$ \\
\hline Total & 36.644 & 23.751 .990 & $100 \%$ & $100 \%$ & 51.107 & 25.788 .670 & $100 \%$ & $100 \%$ & $-28 \%$ & $-8 \%$ \\
\hline
\end{tabular}

Fuente: Elaboración propia en base a datos de los Censos Nacionales Agropecuarios 2002 y 2018 (INDEC).

En el caso de la provincia de Buenos Aires, como lo muestra el Cuadro 2, entre 2002 y 2018 cayó la cantidad de explotaciones agropecuarias en un $28 \%$, mientras que las hectáreas solo lo hicieron en un $8 \%$ (al pasar de 25,8 millones a 23,7 millones $)^{10}$. Esto implica que el tamaño promedio de las explotaciones agropecuarias pasó de 505 hectáreas por unidad en 2002 a 648 en 2018. Si se mira la distribución en materia de número de hectáreas, aquellas explotaciones de hasta 5.000 hectáreas (con excepción de aquellos que tienen hasta 5프) cayó, y en cambio creció la que supera esa cifra. Hasta el año 2002, las unidades de hasta 200 hectáreas eran el $53 \%$ del total y acumulaban el $8 \%$ de las hectáreas productivas. Para el Censo 2018, este grupo había caído al $46 \%$ del total y sus tenencias representaban el $6 \%$ de la superficie. En cambio, las explotaciones de 200 a 2.500 hectáreas crecieron en unidades (pasaron del $44 \%$ al $49 \%$ del total), pero disminuyeron en cantidad de hectáreas bajo control (del $59 \%$ al $54 \%$ ). Finalmente, las mayores explotaciones (más de 2.500 hectáreas), que 
eran 1.742 en 2002, llegaron a las 1.829 en 2018 y aumentaron su participación en la superficie total del 33 al $40 \%$.

Los resultados censales también muestran las tendencias al avance de la agricultura sobre la ganadería que se mencionó previamente en el análisis por áreas bonaerenses. Para el caso de la región pampeana (Buenos Aires, Santa Fe, Córdoba y Entre Ríos), el área dedicada a cultivos anuales avanzó en 2,3 millones de ha (un 14,4\%) entre 2002 y 2018, desplazando a la ganadería, dado que el área implantada con forrajeras (perennes y anuales) decreció 3,9 millones de ha (y los pastizales naturales perdieron 3,7 millones de ha). Ello expresa una tendencia a la relocalización de estas últimas siembras fuera de las provincias pampeanas, epicentro del crecimiento de cultivos cereales y de oleaginosas (Azcuy Ameghino y Fernández, 2019).

Adicionalmente, se advierte que las explotaciones agropecuarias con bovinos cayeron en más de un tercio $(36,7 \%$ ) y aquellas que tienen hembras en tambo lo hicieron en prácticamente dos tercios $(61,4 \%)$ entre ambos censos. Sin embargo, la reducción de los bovinos en tambo fue menor $(30,4 \%)$, en lo que mostraría un proceso de concentración de unidades productivas con mayor rodeo y engorde a corral. En este escenario, signado por un proceso de deterioro del sector lácteo bajo la competencia contra las otras alternativas por el uso del suelo registrado desde los años 2000플, se vio particularmente afectado en 2015-2019 por la mencionada caída del consumo y el aumento de los costos de los insumos (tecnología, energía, forraje) de esta etapa, que reforzaron la concentración en los tambos que producen más de 2.000 lt/día (OCLA, 2020; Rodríguez, 2018).

Al respecto, si bien la concentración es una tendencia general que se verifica en las economías capitalistas, el proceso parece tener particularidades en el caso argentino, donde muy pocos actores tienen «poder de veto» sobre las decisiones de las políticas económicas y el control de la producción y los precios (Azpiazu y otros, 2011). En el sector agrícola, ello incluso se ha verificado en la capacidad de estos sectores de ejercer presión en momentos en que se discutió la movilidad de las retenciones a las exportaciones (Basualdo, 2008). 
Cuadro 4. Comparación entre existencias bovinas y explotaciones agropecuarias (EAP) en la provincia de Buenos Aires. Censos 2002 y 2018 y variación intercensal

\begin{tabular}{l|l|l|l}
\hline Censos & $\mathbf{2 0 1 8}$ & $\mathbf{2 0 0 2}$ & $\mathbf{2 0 1 8 / 2 0 0 2}$ \\
\hline Explotaciones agropecuarias & 24.754 & 39.113 & $-36,7 \%$ \\
\hline Cabezas & 14.997 .102 & 16.612 .170 & $-9,7 \%$ \\
\hline EAP con rodeo de tambo & 1.202 & 3.117 & $-61,4 \%$ \\
\hline Bovinos de tambo & 626.827 & 900.968 & $-30,4 \%$ \\
\hline
\end{tabular}

Fuente: Censos Nacionales Agropecuarios 2002 y 2018.

Por último, los datos censales indican que la cantidad de cabezas se redujo un $9,7 \%$ entre ambos registros $\frac{13}{3}$, a pesar de la recuperación de stock mencionada en las distintas regiones de la provincia entre 2016 y 2019.

\section{b. Comercio exterior en el período de restricción externa: 2012-2019}

Las políticas económicas, comerciales, cambiarias y fiscales adoptadas en 2015-2019 tenían como uno de sus objetivos incrementar la producción y las exportaciones primarias y de manufacturas de origen agropecuario. La provincia de Buenos Aires estaba llamada a ocupar el lugar preponderante en esta estrategia en el marco de su protagonismo en la producción y las exportaciones nacionales. La estrategia se proponía, junto con el endeudamiento externo público, aliviar la problemática de la restricción externa del último gobierno kirchnerista (2012-2015) (Wainer, 2019). 


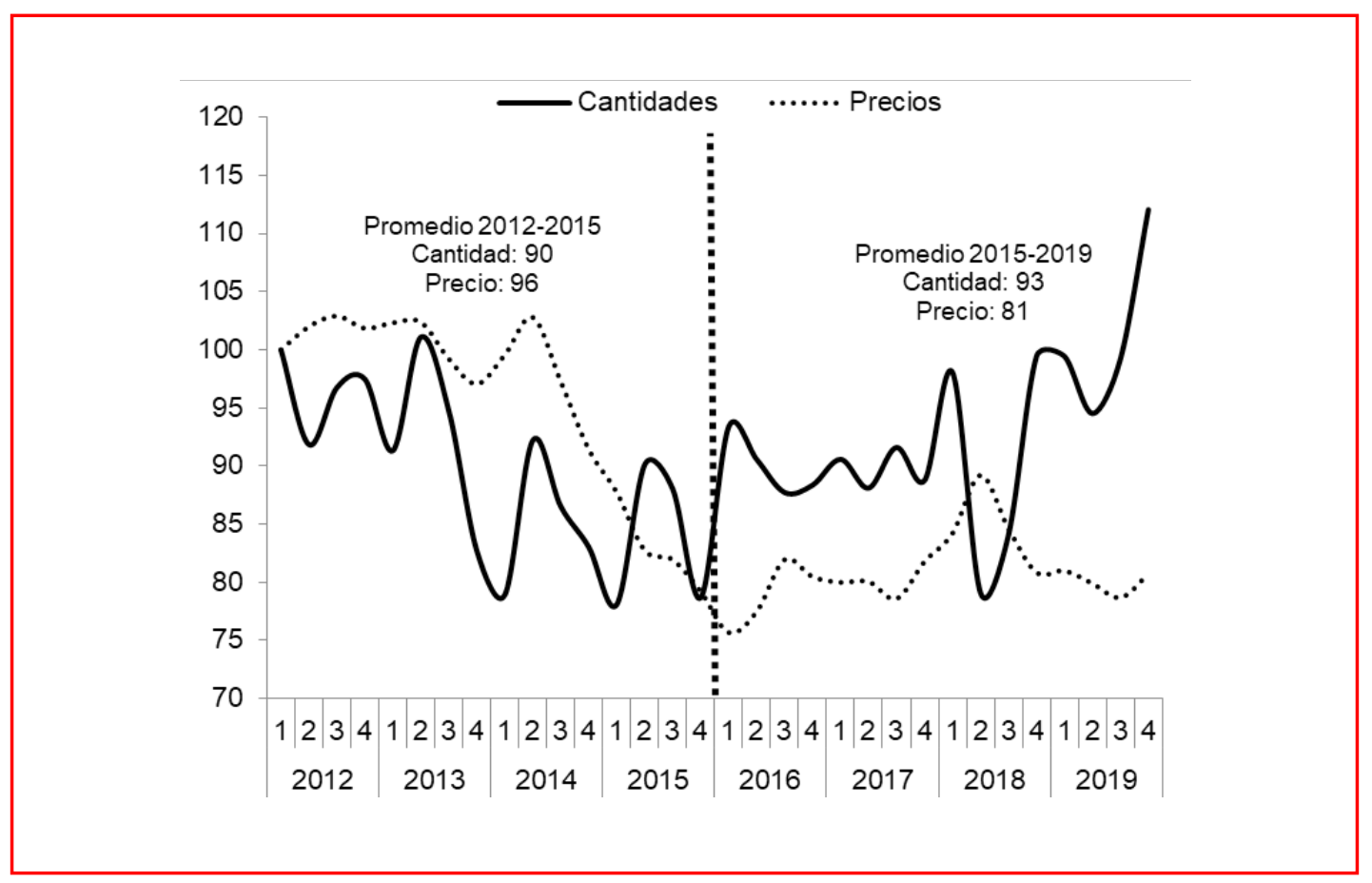

Gráfico 5. Evolución de los índices trimestrales de cantidades (desestacionalizadas) y precios del comercio exterior argentino. I trim. 2012-IV trim. 2019. Base I trim. 2012=100

Fuente: Elaboración propia en base a INDEC.

Una primera aproximación respecto de la evolución de las exportaciones a nivel nacional en 2016-2019 indica que las mismas no mostraron, en cantidades, incrementos sustanciales en relación con la etapa 2012-2015. Se anotó una desmejora de los precios (en promedio, resultaron un $16 \%$ inferiores a los del último gobierno de Cristina Fernández), pero las cantidades registraron valores prácticamente idénticos (con una media de apenas un 1,5\% superior). Sin duda, la sequía de 2018 afectó este comportamiento, pues en 2019 las cantidades aumentaron significativamente.

Un examen más detenido y con foco en la provincia de Buenos Aires muestra que en los cuatro años que van de 2016 a 2019 las exportaciones provinciales acumularon un $13,9 \%$ menos de divisas que en el cuatrienio anterior. La caída más relevante se produjo en manufacturas de origen industrial, en tanto que los productos primarios también aportaron menos divisas (-6,3\%). Levemente mayores fueron las exportaciones de MOA, que aumentaron un $2,9 \%$ y más significativas las de combustibles y energía ( $25 \%$ ). Estos resultados indican entonces que las políticas de apertura, liberalización, desregulación y quita de retenciones no habrían dado las respuestas esperadas para apalancar el comercio y las divisas. 
Bona, Leandro I Tendencias recientes en los cultivos y la producción ganadera en la provincia de Buenos Aires...

Cuadro 5. Exportaciones provinciales acumuladas por grandes rubros. Provincia de Buenos Aires. Millones de dólares. Períodos 2012-2015 y 2016-2019 y variación porcentual

\begin{tabular}{l|l|l|l}
\hline Períodos & $\mathbf{2 0 1 2 - 2 0 1 5}$ & $\mathbf{2 0 1 6 - 2 0 1 9}$ & $\begin{array}{l}\mathbf{2 0 1 6 - 2 0 1 9 /} \\
\mathbf{2 0 1 2 - 2 0 1 5}\end{array}$ \\
\hline Productos primarios & 18.285 & 17.131 & $-6,3 \%$ \\
\hline Manufacturas de Origen Agropecuario (MOA) & 21.944 & 22.576 & $2,9 \%$ \\
\hline Manufacturas de Origen Industrial (MOI) & 50.966 & 37.221 & $-27,0 \%$ \\
\hline Combustible y Energía & 3.988 & 4.986 & $25,0 \%$ \\
\hline Total & $\mathbf{9 5 . 1 8 3}$ & $\mathbf{8 1 . 9 1 4}$ & $\mathbf{- 1 3 , 9 \%}$ \\
\hline
\end{tabular}

Fuente: Elaboración propia en base a datos del Ministerio de Economía de la Provincia de Buenos Aires.

A pesar de lo anterior, una apertura más detallada de las exportaciones provinciales, concentrada en los seis rubros que explicaron entre el $53 \%$ y el $63 \%$ de las exportaciones de MOA y PP en los últimos diez años, indica que hubo dos sectores que dieron un giro relevante a partir de las mencionadas políticas entre 2015 y 2019: carnes y sus preparados, y cereales (especialmente trigo y maíz). En el caso de la carne, el cambio es sustancial porque sufría un declive al menos desde 2010, mientras que en cereales, se inició una recuperación que llevó los valores a niveles comparables con los de 2013. Ahora bien, en el caso del resto de los rubros seleccionados, el rendimiento ha sido mucho menos auspicioso, con un detalle singular: la molienda y los aceites, rubros de mayor incorporación de valor agregado, mostraron tendencias declinantes en relación con 2015. Ese desempeño se explica, en parte, por la escasa política de segmentación por agregación de valor implementada entre 2015 y 2019, que favoreció las producciones primarias (Rodríguez, 2018). Asimismo, semillas y frutos oleaginosos y residuos alimentarios tampoco tuvieron un mejor desempeño que en el período 2012-2015. 


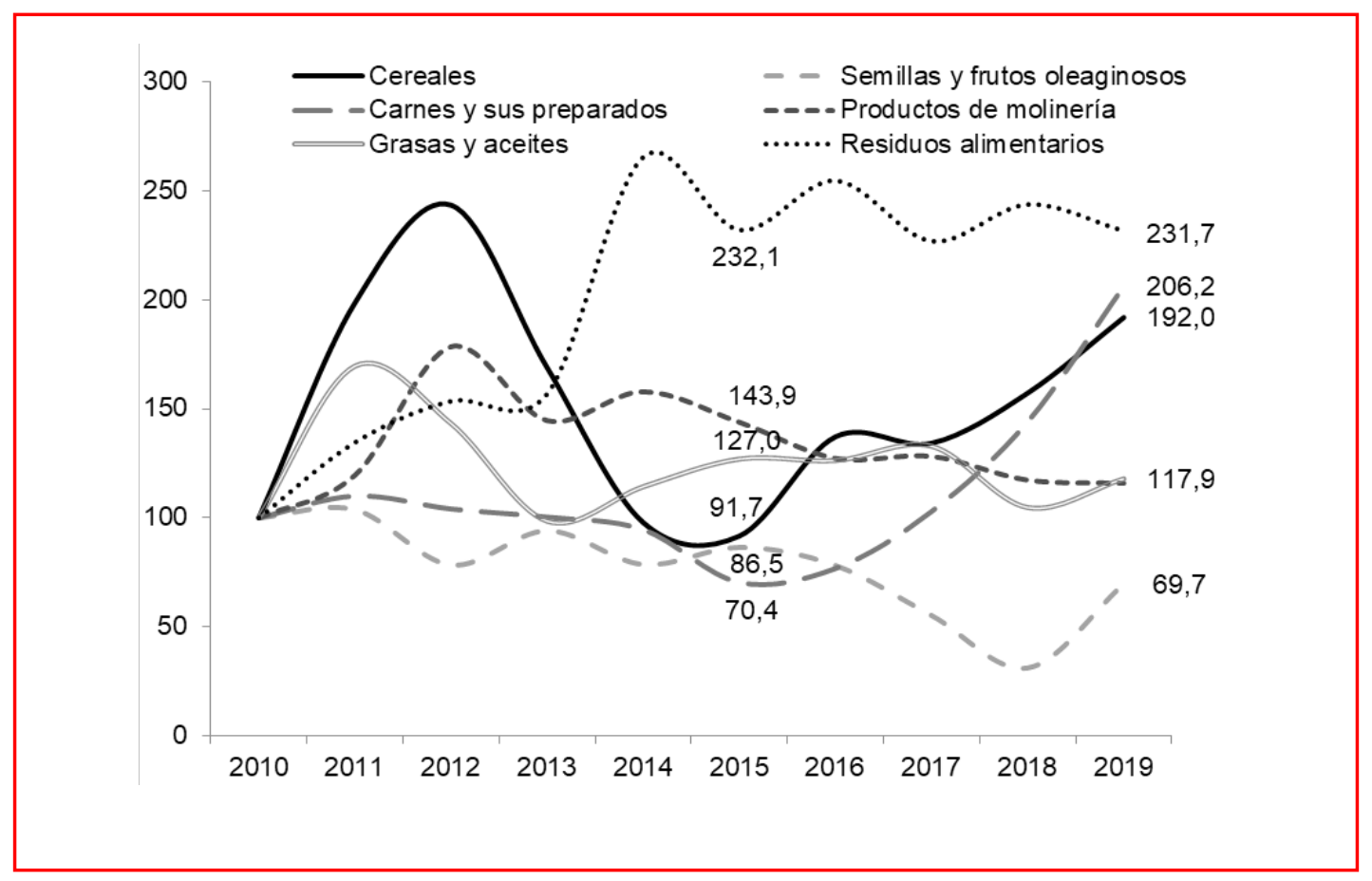

Gráfico 6. Evolución de las exportaciones de complejos seleccionados de la provincia de Buenos Aires. Años 2010-2019. Base $2010=100$

Fuente: Elaboración propia en base a datos del Ministerio de Economía de la Provincia de Buenos Aires.

\section{Reflexiones finales}

Se ha mostrado en este trabajo que Argentina, desde mediados de la década del 90 y bajo el patrón de acumulación de la valorización financiera, introdujo un cambio tecnoproductivo que redefinió el uso del suelo fértil y, gracias a ello, incrementó la productividad agrícola de manera sustancial. Si bien durante los gobiernos kirchneristas (2003-2015) se produjeron importantes cambios en la economía política, cuestionando la lógica del patrón de acumulación del período 1976-2001, en el siglo XXI aquellas modificaciones tecnológicas se combinaron con un ciclo alcista en el precio de los commodities (especialmente soja) que generó un significativo aumento de las exportaciones y la renta. A su vez, la ganadería resultó relativamente desplazada y sufrió una crisis con liquidación de vientres en 2008-2011. El período 2012-2015, bajo el signo de la restricción externa, estuvo marcado por un aumento en el conjunto de políticas de intervención sectorial que granjearon las disputas por la apropiación y gestión de las rentas, y en algunos casos tuvieron un impacto negativo en términos de rotación de cultivos, generaron desincentivos a la ganadería e intensificaron la concentración de la propiedad. 
Los cambios introducidos durante el período 2015-2019 buscaron revertir algunas de las tendencias previas (caída de cultivos y actividades alternativos a la soja) y ratificar y profundizar otras (inserción primario exportadora). Para ello el gobierno nacional se abocó a la desregulación sectorial y cambiaria (reducción de derechos de exportación, celebración de acuerdos comerciales, eliminación de permisos, cupos, certificados), combinada con un tipo de cambio que benefició relativamente al sector primario exportador.

La evolución de las producciones primarias en las regiones de la provincia de Buenos Aires bajo análisis muestra un factor común para el período 2015-2019: se verificó un crecimiento de los cultivos alternativos a la soja, particularmente de maíz y trigo, que detuvieron e hicieron retroceder parcialmente la siembra de la oleaginosa estrella. El epicentro de estos cambios fueron las regiones del norte y centro de la provincia, aunque el fenómeno se registró de manera general. Por su parte, la ganadería recuperó rentabilidad y mercados externos, mejorando la tendencia iniciada en 2012 de recuperación de madres, en un proceso que tuvo mayor protagonismo en la Cuenca del Salado y el Sudoeste. Por cierto, en muchos casos se verificó un incremento simultáneo tanto de la superficie sembrada como de la cantidad de bovinos (gracias a un manejo más intensivo de la tenencia de animales y la extensión del engorde a corral). Ambos resultados se contaban entre los propósitos explícitos de la administración nacional cuando se eliminaron las retenciones en diciembre de 2015.

Si bien estas evidencias dan cuenta de mejoras a partir de la reducción de la tendencia al monocultivo y la recuperación de la ganadería, la ausencia de políticas segmentadas (retenciones escalonadas) habría conspirado contra una mayor agregación de valor en la cadena primario exportadora. De esta manera, las exportaciones provinciales entre 2016 y 2019 mostraron un comportamiento decepcionante en materia de generación de divisas (no alcanzaron los registros de 2012-2015, aunque allí incidieron tanto un escaso dinamismo en precios internacionales como la sequía de 2018) y se concentraron en bienes de menor agregación de valor, con tendencias decrecientes en molienda y aceites.

Por su parte, el proceso de concentración que registra el sector agropecuario en los últimos cuarenta años se ratificó a partir de las primeras evidencias del Censo Nacional Agropecuario (2018) en la provincia de Buenos Aires. Crecieron las explotaciones de mayor escala en la provincia (más de 5.000 hectáreas) y desaparecieron especialmente las de menor superficie (5 a 200 hectáreas). En un proceso que se aceleró desde los albores del siglo XXI, las políticas económicas recientes (2015-2019) no habrían contribuido a reducir 
Bona, Leandro I Tendencias recientes en los cultivos y la producción ganadera en la provincia de Buenos Aires...

esta tendencia, sino que el aumento en los costos de los insumos y la mayor transferencia de renta al sector habrían ratificado estos síntomas.

Por último, la combinación de una caída de los salarios y jubilaciones reales con el aumento de los precios implícitos del sector indicarían que el mercado interno no fue una prioridad de la nueva administración.

\section{Agradecimientos}

Agradezco a Eduardo Basualdo y Pablo Manzanelli, con quienes trabajamos en estas temáticas; ellos revisaron versiones preliminares de este texto. También quiero agradecer a los/as evaluadores/as anónimos/as por sus críticas y sugerencias. No obstante lo anterior, los posibles errores $u$ omisiones que pueda haber son exclusiva responsabilidad del autor. Este trabajo fue realizado en el marco del proyecto «Condicionamientos estructurales, macroeconómicos y sectoriales y sus manifestaciones en el sector externo» (PICT 2016-3306), que cuenta con el patrocinio de la Agencia Nacional de Promoción Científica y Tecnológica del Ministerio de Ciencia, Tecnología e Innovación Productiva.

\section{Notas}

1. Se sucedieron tanto investigaciones (ver Carrasco y otros, 2010) como movilizaciones de comunidades de damnificados en relación con los daños medioambientales (http:// reduas.com.ar/declaracion-de-pueblos-fumigados-de-cordoba-2019/), así como críticas sobre cómo los efectos de la falta de rotación de cultivos y la intensificación de la soja erosionaron la fertilidad de la tierra (ver Reboratti, 2010). « volveR

2. Otras investigaciones, si bien presentan volúmenes distintos de renta (debido a diferencias metodológicas en las estimaciones), coinciden en las tendencias. Al respecto, ver Bus (2013), Iñigo Carrera (2007) y Sturzenegger (2015). « VOLVER

3. Los resultados de las medidas (particularmente retenciones) sobre la protección del mercado interno habrían sido menos efec- tivos que sobre la recaudación fiscal. Sin embargo, en un contexto de protección de los salarios reales, el consumo de carnes, leches y alimentos creció aun en contexto de restricción externa (2012-2015) (Bona, 2021). « VOLVER

4. Utilizando el índice de precios de INDEC, entre enero de 2016 y marzo de 2018 el tipo de cambio real fue, en promedio, un $7 \%$ más alto que en el promedio del año 2015, mientras que desde ese momento hasta diciembre de 2019 resultó un 41\% superior al de aquel año. La transferencia de ingresos que implicó la devaluación en la economía argentina se puede constatar en Wainer (2016). « OLLVER

5. Confederaciones Rurales Argentinas (CRA) y Sociedad Rural Argentina (SRA) son las entidades que nuclean a los propietarios 
Bona, Leandro I Tendencias recientes en los cultivos y la producción ganadera en la provincia de Buenos Aires...

de mayor tamaño dentro de la llamada mesa de enlace (compuesta además por Coninagro y Federación Agraria Argentina). « VOLVER

6. La decisión se articulaba con la desregulación de la cuenta capital ejecutada por el Banco Central, que eliminó los plazos mínimos de inversiones de cartera y el tope de compras de moneda extranjera para cualquier fin. « VOLVER

7. Existen varios trabajos que han presentado formas de regionalización de la provincia de Buenos Aires con otros criterios. Solo para citar algunos de los más recientes, ver Tauber y otros (2008), Ministerio de Producción, Ciencia y Tecnología de la Provincia de Buenos Aires (2013), Ministerio de Economía de la Provincia de Buenos Aires (2011, 2015 y 2017) y Banco de la Provincia de Buenos Aires (2013). « volveR

8. El Coeficiente de Orientación Productiva surge de relacionar la adición del novillo y novillito con la vaca. Hasta 0,4 (predomina la actividad de cría); entre 0,4-0,6 (tiene cierta incidencia la actividad de ciclo completo); entre 0,6-1,2 (predomina el ciclo completo); 1,2-1,8 (tiene cierta incidencia la actividad de invernada); más de 1,8 (predomina la actividad de invernada). « VolveR

9. Cabe señalar que si bien hubo un Censo Nacional Agropecuario en 2008, sus resultados han sido desestimados debido a que se realizó en el marco del conflicto agra- rio. Debido a las dificultades de obtención de la información, las evidencias resultaron muy acotadas y no son comparables a las de los censos precedentes. « VOLVER

10. La reducción en la superficie de las EAP obedecería tanto a un incremento del uso no agropecuario de la tierra (avance urbano y otros) como a problemas de barrido censal (Azcuy Ameghino y Fernández, 2019). « VOLVER

11. Por cierto, al observarse una mayor cantidad de EAP de hasta 5 ha (2.926 en 2018 versus 2.180 en 2002) que abarcan una menor superficie (5.664 versus 6.247), ello indicaría que se redujo la superficie promedio de estos pequeños productores. « VOLVER

12. Cabe agregar que las políticas de intervención sobre el sector lácteo bajo el kirchnerismo estuvieron marcadas por el aumento de las retenciones, que inicialmente (2002) eran del $5 \%$, y luego pasaron al $10 \%$ para leche en polvo y $15 \%$ para quesos en 2005. En 2008 llegaron ambas al 33,5\%. Ello generó un proceso de concentración de las mismas sobre los productores y por ende la desaparición de tambos chicos (Grimaldi, 2018). « VOLVER

13. Los datos de bovinos totales del Censo 2018 resultan muy inferiores a los registrados por SENASA, aunque lo propio ocurre con el Censo de 2002, por lo que se considera ambos registros comparables, menos en nivel que en tendencia. « vOLveR 
Bona, Leandro I Tendencias recientes en los cultivos y la producción ganadera en la provincia de Buenos Aires...

\section{Referencias bibliográficas}

ANLLÓ, G.; Bisang, R. y Katz, J. (2015). Aprendiendo con el agro argentino. De la ventaja comparativa a la ventaja competitiva. Documento del BID. Disponible en: https:// publications.iadb.org/publications/spanish/ document/Aprendiendo-con-el-agro-argentino-De-la-ventaja-comparativa-a-la-ventaja-competitiva-El-rol-de-las-KIBs.pdf

ARCEO, E. (2003). Argentina en la periferia próspera. Renta internacional, dominación oligárquica y modo de acumulación. Buenos Aires: UNQ.

ARCEO, E. y Basualdo, E. (1999). Las tendencias a la centralización del capital y la concentración del ingreso en la economía argentina durante la década del noventa. Cuadernos del Sur, 29, 23-38.

ARCEO, E.; Arceo, N. y Basualdo, E. (2009). La crisis mundial y el conflicto del agro. Buenos Aires: UNQ - Página/12 - Centro Cultural de la Cooperación.

AZCUY AMEGHINO, E. y Fernández, D. (2019). El Censo Nacional Agropecuario 2018. Visión general y aproximación a la región pampeana. Centro Interdisciplinario de Estudios Agrarios (FCE-UBA). Disponible en: https://bichosdecampo.com/wp-content/ uploads/2019/12/cna 2018 azcuy ameghino fernandez-1.pdf

AZPIAZU, D.; Manzanelli, P. y Schorr, M. (2011). Concentración y extranjerización. La Argentina en la postconvertibilidad. Buenos Aires: Capital Intelectual.

BANCO DE LA PROVINCIA DE BUENOS AIRES (2013). Identificación, cuantificación y análisis de cadenas productivas en la provincia de Buenos Aires. La Plata.
BASUALDO, E. (2010). Estudios de historia económica argentina. Desde mediados del siglo XX a la actualidad. Buenos Aires: Siglo XXI.

BASUALDO, E. (ed.) (2017). Endeudar y fugar. Un análisis de la historia económica argentina de Martínez de Hoz a Macri. Buenos Aires: Siglo XXI editores.

BASUALDO, E. (2008). El agro pampeano: sustento económico y social del actual conflicto en la Argentina. Cuadernos del CENDES, 25(68), 29-54.

BASUALDO, E. (2019). Fundamentos de economía política: Los patrones de acumulación, de los clásicos al neoliberalismo del siglo XXI. Buenos Aires: Siglo XXI editores.

BASUALDO, E.; Manzanelli, P. y Bona, L. (2019). Estructura económica y desintegración productiva en tiempos recientes. Parte I: Una visión general de la estructura económica provincial, y Parte II: El extenso y heterogéneo ámbito provincial. En Alonso y otros, Radiografía de la provincia de Buenos Aires. Crisis de un territorio en disputa. Buenos Aires: Siglo XXI editores.

BIODIVERSIDAD EN AMÉRICA LATINA Y EL CARIBE (2011). Engordes a corral en Argentina. Una amenaza para la salud, el ambiente y la población campesino-indígena. Edición especial para el Foro Social de las Américas.

BOLSA DE COMERCIO DE ROSARIO (BCR) (2018). Perspectivas 2018/19 para el agro argentino, Equipo DIyEE, XXXVI (1861).

BONA, L. (2019). ¿Neoliberalismo hegemónico? Apuntes sobre el Estado, el bloque de poder y la economía política en la Argentina reciente (2016-2018). Pilquen. Sección Ciencias Sociales, 22, 39-54. 
Bona, Leandro I Tendencias recientes en los cultivos y la producción ganadera en la provincia de Buenos Aires...

BONA, L. (2021). ¿Del granero al supermercado del mundo? El agro, la generación de divisas y los cambios en las políticas sectoriales en el siglo XXI. En Wainer (ed.), ¿Por qué siempre faltan dólares? Las causas estructurales de la restricción externa en la economía argentina. Buenos Aires: Siglo XXI.

BRAUN, O. (1970). Desarrollo del capital monopolista en Argentina. Buenos Aires: Tiempo Contemporáneo.

BUS, A. (2013). La renta diferencial agrícola en Argentina (1986-2008). Cálculo por departamento y ajuste econométrico. Tesis doctoral FCE-UBA.

CANTAMUTTO, F. y López, E. (2018). El orden social kirchnerista entre la economía y la política. En Schorr, M. (coord.). Entre la década ganada y la década perdida. La Argentina kirchnerista. Buenos Aires: Batalla de Ideas (pp. 11-51).

CARRASCO, A. y otros (2010). Glyphosate-Based Herbicides Produce Teratogenic Effects on Vertebrates by Impairing Retinoic Acid Signaling. Chemical Research and Toxicology, 23(10), 1586-1595.

CENSO NACIONAL AgROPECUARIO (2018). Resultados preliminares. INDEC.

CUELLO, M. (2016). El cambio tecnológico en la producción sojera argentina: análisis de la difusión del paradigma de las TICs y la conformación de un Sistema Nacional de Innovación (1995-2014). Tesis Doctoral, Universidad Nacional de Quilmes, Secretaría de Posgrado, Doctorado en Ciencias Sociales y Humanas.

DIAMAND, M. (1973). Doctrinas económicas, desarrollo e independencia. Buenos Aires: Paidós.
FERRER, A. (2008). La economía argentina. Desde sus orígenes hasta los albores del siglo XXI. Buenos Aires: FCE.

FURTADO, C. (1972). Teoría y política del desarrollo económico. México: Siglo XXI editores.

GRIJALVA, D. (2014). El fin del súper ciclo de los Commodities y su impacto en América Latina. Koyuntura, 48(7), 1-8.

GRIMALDI, S. (2018). La disputa por la renta durante la primera década del siglo XXI en Argentina. Estado, corporaciones y partidos políticos (2001-2014). Tesis doctoral, FaHCE-UNLP.

INSTITUTO DE PROMOCIÓN DE LA CARNE VACUNA (IPCVA) (2018). Actualidad y perspectivas del mercado de carnes. Presentación ing. agrónomo J. Bifaretti, Carlos Tejedor, mayo.

INSTITUTO NACIONAL DE TECNOLOGÍA AGROPECUARIA (INTA) (2015). Caracterización de la producción bovina. Buenos Aires-Corrientes-La Pampa-Chaco-Misiones. Sistema de Monitoreo del Sector de la Carne Bovina. Serie 1, diciembre.

IÑIGO CARRERA, J. (2007). La renta de la tierra. Formas, fuentes y apropiación. Buenos Aires: Imago Mundi.

LÓPEZ, A. y Pascuini, P. (2017). Política comercial, inserción internacional y desarrollo productivo. Documento de Trabajo 5, Secretaría de Comercio, Ministerio de Producción.

MARESCA, S. (2018). Situación actual y perspectivas de la Cuenca del Salado. INTA-EEA, Cuenca del Salado. Disponible en: https// www.inta.gob.ar/sites/default/files/situacion de la cuenca.pdf 
Bona, Leandro I Tendencias recientes en los cultivos y la producción ganadera en la provincia de Buenos Aires...

MINISTERIO DE AGROINDUSTRIA (2020). Estimaciones agrícolas. Disponibles en: http// www.datosagroindustria.gob.ar.

MINISTERIO DE AGROINDUSTRIA (2018). Resultados económicos ganaderos. Secretaría de Ganadería. Informe trimestral n. ${ }^{\circ} 27$, septiembre.

MINISTERIO DE ECONOMÍA DE LA PROVINCIA DE BUENOS AIRES (2015). Caracterizar para planificar. Bases para el desarrollo con equidad territorial. Documento de Trabajo n. ${ }^{\circ}$. MINISTERIO DE ECONOMÍA DE LA PROVINCIA DE BUENOS AIRES (2011). Plan de Regionalización. La estrategia de desarrollo para la provincia. La Plata: Ministerio de Economía de la PBA.

MINISTERIO DE ECONOMÍA DE LA PROVINCIA DE BUENOS AIRES (2017). El gran esfuerzo de planificar el desarrollo en la provincia de Buenos Aires. Programación del Desarrollo Territorial. Diagnóstico preliminar y líneas de acción para la discusión. La Plata.

MINISTERIO DE PRODUCCIÓN, CIENCIA Y TECNOLOGÍA DE LA PROVINCIA DE BUENOS AIRES (2013). Plan Estratégico Productivo Buenos Aires 2020. La Plata: Ministerio de Producción, Ciencia y Tecnología de la PBA.

OBSERVATORIO DE BIOECONOMÍA, SECRETARÍA DE AGROINDUSTRIA DE LA PROVINCIA DE BUENOS AIRES (2019). Datos agroindustriales, informes de coyuntura. Disponible en: https://www.gba.gob.ar/desarrollo agrario/ observatorio de bioeconomia

OBSERVATORIO DE LA CADENA LÁCTEA ARGENTINA (OCLA) (2020). Estadísticas e informes disponibles en http//ocla.org.ar.

O'DONNELL, G. (1977). Estado y alianzas en Argentina, 1956-1976. Desarrollo Económico, 16(64), 523-554.
PÁEZ, S. (2016). Soja en Argentina a principios del siglo XXI: el sistema agropecuario y la competencia por el uso del suelo productivo. Cuadernos de Economía Crítica, 3(5), 135-172.

PALMIERI, P. (2015). Generación y distribución de la renta agraria en la Argentina una aproximación empírica para el período 2002-2013. Realidad Económica, 295, 32-52.

PANIGO, D.; Bona, L. y Wahren, P. (2019). Contexto internacional, modos de desarrollo comparados y sus enseñanzas para el diseño de la nueva política industrial argentina. Voces en el Fénix, 14, 96-197.

PÉREZ TRENTO, N. (2019). Las transformaciones globales en la producción de semillas y su impacto en el conflicto por el uso propio en Argentina. Ciencia, Docencia y Tecnología, 30.

PORDOMINGO, A. (2013). Feed-lot. Alimentación, diseño y manejo. EEA «Guillermo Covas», INTA Anguil, Facultad de Ciencias Veterinarias UNLPam.

REBORATTI, C. (2010). Un mar de soja: la nueva agricultura en Argentina y sus consecuencias. Revista de Geografía Norte Grande, 45, 63-76.

RePETto, J. (2019). El último Censo Agropecuario muestra concentración de la producción agropecuaria. Disponible en: http://www.iade.org.ar/noticias/el-ultimo-censo-agropecuario-muestra-concentracion-de-la-produccion-agropecuaria.

RODRÍGUEZ, J. (2018). Problemas actuales del agro argentino. VII Jornada Debate Cátedra Libre de Estudios Agrarios Ing. Agr. Horacio Giberti. Buenos Aires, mayo. 
Bona, Leandro I Tendencias recientes en los cultivos y la producción ganadera en la provincia de Buenos Aires...

SANTARCÁNGELO, J. y Fal, J. (2009). Producción y rentabilidad en la ganadería argentina: 1980-2006. Mundo Agrario, 10(19).

SECRETARÍA DE AGRICULTURA, GANADERÍA Y PESCA-PNUD (1996). Zonificación Agroeconómica y Sistemas Productivos Predominantes, Sub Proyecto «Riesgo y Seguros Agropecuarios» PROSAP ARG 96/006, Documento II.

STURZENEGGER, A. (2015). Renta agrícola y macroeconomía, tecnología, precios externos y política comercial externa. Argentina 2000-2015. Serie de informes técnicos del Banco Mundial en Argentina, Paraguay y Uruguay, n. 2 .

TAUBER, F.; Delucchi, D.; Martino, H.; Sánchez, A.; Frediani, J.; Vázquez, V. y Nigou, P. (2008). Propuesta metodológica para la regionalización de la provincia de Buenos Aires. Dirección de Asuntos Municipales, UNLP.
TRIGO, E. (2016). Veinte años de cultivos genéticamente modificados en la agricultura argentina. AngenBio. Disponible en: https://www.fiba.org.ar/wp-content/ uploads/2016/12/informe20gm.pdf

VÉRTIZ, P. (2015). El avance de los agronegocios en regiones marginales del agro pampeano: concentración de la producción y tensiones entre las fracciones del capital agrario. Mundo Agrario, 16(33).

WAINER, A. (2016). ¿El populismo imposible? Economía y política en la Argentina reciente. Épocas. Revista de Ciencias Sociales y Crítica Cultural, 2.

WAINER, A. (2018). La restricción externa al crecimiento en la Argentina en el período kirchnerista (2003-2015). Semestre Económico, 21, 95-122.

WAINER, A. (2019). ¿Desarrollismo o neoliberalismo? Una economía política del macrismo. Realidad Económica, 48, 33-68. 